\title{
Restrição externa e crescimento simulando um modelo multissetorial aberto *
}

\author{
Maria Isabel Busato ** \\ Mario Luiz Possas ${ }^{* * *}$
}

\begin{abstract}
Resumo
$\mathrm{O}$ artigo busca discutir a dinâmica do crescimento econômico das economias em desenvolvimento a partir do Princípio da Demanda Efetiva keynesiano e kaleckiano e dos Modelos de crescimento liderado pela demanda e restrito pelo balanço de pagamentos, concebidos pela Cepal e desenvolvidos principalmente por Thirlwall. Para tanto, desenvolveu-se um modelo teórico de simulação capaz de captar os efeitos sobre as taxas de crescimento e sobre as condições externas quando a economia estilizada é submetida a diferentes padrões de crescimento. As principais conclusões foram: i) as taxas de crescimento de uma economia cuja dinâmica é exclusivamente impulsionada pelas condições internas (de política expansionista) serão em algum momento restringidas por imposições do balanço de pagamentos; e ii) se os setores produtivos conseguem introduzir uma dinâmica inovativa capaz de aumentar a competitividade de seus produtos, aumentando o coeficiente de exportação, a economia crescerá impulsionada pela dinâmica interna, postergando, mas não eliminando o risco de vulnerabilidade externa.
\end{abstract}

Palavras-chave: Demanda efetiva; Dinâmica capitalista. Crescimento econômico. Restrição externa; Modelos de simulação.

\begin{abstract}
External constriction and economic growth: an open multisectoral simulation model

This paper discusses the dynamics of economic growth in developing economies using the Keynesian and Kaleckian effective demand principle as well as the balance of payments constrained demand-led growth models, conceived by ECLAC (Economic Commission for Latin America and the Caribbean) and developed by Thirlwall. To this effect, a computer simulation model was developed to capture the effects on the balance of payments and on economic growth rates under different growth patterns. The main conclusions drawn were: i) growth rates of an economy in which the dynamics are exclusively driven by internal conditions will, from a certain point, be constrained by the rise in external vulnerability; ii) if productive sectors are able to introduce innovative dynamics increasing the competitiveness of their products and therefore the export coefficients, economic growth will be driven by internal demand, postponing, although not precluding, the risk of foreign vulnerability.
\end{abstract}

Keywords: Principle of effective demand; Capitalist dynamics; Economic growth; Foreign constraint; Simulation models.

JEL O41, O11, C63.

* Artigo recebido em 18 de junho de 2014 e aprovado em 22 de janeiro de 2016.

${ }^{* *}$ Professora do Instituto de Economia da Universidade Federal do Rio de Janeiro (IE-UFRJ) / Membro do Grupo de Dinâmica Econômica, Rio de Janeiro, RJ, Brasil. E-mail: maria.busato@ie.ufrj.br.

*** Professor Titular do IE-UFRJ e membro do Grupo de Dinâmica Econômica, Rio de Janeiro, RJ, Brasil.

E-mail: mariopossas@gmail.com. 


\section{Introdução}

$\mathrm{O}$ artigo tem como objetivo contribuir para a análise da dinâmica macroeconômica sob restrição externa, buscando examinar algumas das circunstâncias em que a restrição se torna mais efetiva em limitar o crescimento econômico. Parte-se de um modelo macroeconômico multissetorial ${ }^{1}$ que tem como elementos teóricos norteadores: i) o PDE (Princípio da Demanda Efetiva) keynesiano e kaleckiano - e seus efeitos multiplicadores e aceleradores - que fundamenta as decisões de produzir e de investir dos agentes econômicos; ii) a incerteza fundamental e a tentativa dos agentes de se proteger dela utilizando o "comportamento da maioria ou da média"2; e iii) as contribuições analíticas a respeito da restrição externa iniciadas pela Cepal e amplamente difundidas pelos trabalhos de Thirlwall.

Para a análise dinâmica serão utilizadas técnicas de simulação, um instrumental analítico computacional por meio do qual se configurou uma economia estilizada - com características das economias em desenvolvimento e inspirada particularmente em alguns elementos encontrados na economia brasileira - dividida em setores e aberta aos fluxos externos (comerciais e financeiros).

O emprego da técnica de simulação, ao admitir trajetórias em aberto (sem equilíbrios tendenciais), possibilita analisar os efeitos da restrição externa sobre o crescimento a partir de diferentes cenários. Este instrumental mostra-se mais adequado para o modelo adotado (elevado número de equações e múltiplas interações entre as variáveis). A análise da trajetória (soluções) pode ser obtida com maior flexibilidade e realismo por meio da simulação computacional, cuja solução numérica depende das hipóteses e das condições iniciais, bem como dos valores dos parâmetros.

Dado este objetivo mais geral, o artigo pretende:

i) simular o crescimento da economia estilizada induzido pela dinâmica estritamente interna - gasto público - e avaliar os efeitos sobre a trajetória de crescimento com e sem reação dos agentes à piora das condições externas. Pretende-se observar se surge restrição endogenamente como resultado do crescimento induzido;

ii) analisar o resultado sobre a dinâmica econômica de longo prazo do efeito combinado de crescimento induzido pela dinâmica interna associado a uma mudança na competitividade, implicando mudanças nos coeficientes de importação e exportação setoriais.

(1) Parte-se do modelo macroeconômico multissetorial desenvolvido por Possas; Dweck e Reif (2004) e de Reif (2006).

(2) Keynes ([1937] 1984, p. 169). 
A hipótese central é que, em alguma medida, o crescimento econômico é condicionado pelo grau de restrição externa enfrentado. Esta, por sua vez, depende do grau de desenvolvimento do país (estrutura industrial e sua consequente pauta de exportação), sendo mais significativa em países em desenvolvimento.

Além desta introdução, apresentam-se na primeira seção, de forma resumida, os elementos teóricos norteadores da pesquisa. Na segunda serão apresentadas as relações causais propostas e algumas equações do modelo teórico. Na terceira seção serão apresentados os resultados das simulações. Na última seção serão extraídas algumas conclusões.

\section{Demanda efetiva e o papel da restrição externa}

As contribuiçõos de Keynes significaram uma alternativa à forma predominante (anterior e atual) de pensar os determinantes do nível e da taxa de crescimento da economia. As flutuações do nível de atividade são para Keynes, em última análise, fruto da atuação da demanda efetiva, mais especificamente das decisões capitalistas de investir. Ao evocar o PDE, pelo qual a renda não tem existência independente do gasto, sendo deste um produto instantâneo (Possas (1987) -, ele estabeleceu uma teoria geral da determinação do produto e do emprego com base no gasto em consumo e em investimento, variável mais sujeita a repentinas e amplas flutuações (Keynes, [1937] 1984, p. 178). Ademais, investir significa trocar algo certo por uma conjectura, pois a decisão de investir é efetuada com base em expectativas sob incerteza, que poderão ou não se verificar. Logo, o investimento é o fator mais relevante para explicar a dinâmica.

A despeito de Keynes não ter desenvolvido uma teoria completa da dinâmica econômica, forneceu os elementos para que, a partir do PDE, se inaugurasse uma nova forma de interpretar teoricamente as causas das flutuações do produto e do emprego, abrangendo tanto as flutuações econômicas quanto uma possível tendência de longo prazo.

Contemporâneo de Keynes, Kalecki ([1954] 1983) desenvolveu uma teoria da dinâmica capitalista - mais completa do ponto de vista analítico - a partir do PDE, só que bem distinta da formulada por Keynes. O exclusivo enfoque dado por Kalecki no resultado ex post (na validação da produção pelas vendas) tornou mais evidente a essência do PDE: garantidor "da determinação unilateral das receitas (rendas) pelos gastos” (Possas, 2001, p. 101).

No modelo teórico construído por M. Kalecki ([1954] 1977), a interação entre os efeitos multiplicador e acelerador do investimento dão lugar à uma dinâmica cíclica associada às decisões de investir, as quais são guiadas pelo princípio do ajustamento do estoque de capital de forma que os efeitos 'demanda' e o efeito 
'capacidade' criam conjuntamente uma dinâmica cíclica do investimento e, como consequência, do produto e do emprego.

A partir dos anos 60 e 70, os modelos de crescimento liderado pela demanda, sob a égide do PDE, ganharam um importante ingrediente quando se estendeu a análise restrita das economias fechadas para economias abertas em geral e para as subdesenvolvidas, em particular. O multiplicador do comércio exterior de Harrod ([1933] 1962) foi a base para o desenvolvimento desses modelos. Seguindo esse caminho, contribuíram significativamente: i) Kaldor, com os possíveis valores do produto que equilibrariam o balanço de pagamentos e com seu modelo de crescimento liderado pelas exportações, o qual não faz parte do escopo deste artigo; e ii) Thirlwall, com a formalização e a extensão das proposições de Kaldor, formulando a conhecida Lei de Thirlwall. Sabe-se, porém, que antes do desenvolvimento desses modelos, a escola cepalina, notadamente Prebisch, já tinha argumentado sobre o papel restritivo que o balanço de pagamentos poderia ter para o crescimento das economias periféricas, em virtude do tipo de inserção externa, de divisão internacional do trabalho e, portanto, do nível de industrialização dos países da região, implicando que a compreensão do crescimento econômico de tais economias não poderia prescindir da discussão acerca de sua estrutura produtiva.

$\mathrm{Na}$ abordagem do crescimento liderado pela demanda, os níveis e especialmente as taxas de crescimento das economias divergem ao longo do tempo, especialmente em decorrência das diversas restrições que se impõem ao crescimento da demanda. Uma das mais relevantes restrições que enfrentam economias abertas sem moeda conversível é a restrição imposta pela escassez de divisas. Fatos estilizados das trajetórias históricas dos países desenvolvidos e dos periféricos evidenciam o papel das restrições externas para o crescimento econômico. Vejamos agora, de forma bastante sintética, essa questão a partir de algumas abordagens destacadas: a cepalina e a de Thirlwall.

O início da discussão cepalina sobre restrição externa é datada de fins nos anos 40, quando se buscou analisar o caráter estrutural da restrição do balanço de pagamentos (BP) e seus efeitos para o crescimento econômico dos países periféricos, sobretudo os latino-americanos, destacando os efeitos restritivos ao crescimento decorrentes da vulnerabilidade externa, fruto do tipo de inserção externa do país e do seu papel na divisão internacional do trabalho. Isto implicou a ideia de que a discussão sobre crescimento econômico e restrição externa em economias periféricas não poderia prescindir da questão da estrutura produtiva daqueles países.

Para Prebisch, a restrição de divisas - decorrente da especialização exportadora de produtos com baixa elasticidade-renda e da importação de produtos de alta elasticidade-renda - impedia o avanço pleno da industrialização e do crescimento da região. Se a elasticidade-renda das importações de manufaturas 
supera a de produtos agrícolas, o crescimento com equilíbrio em BP somente seria alcançado se os países periféricos crescessem a taxas inferiores às dos centrais.

Nessa perspectiva, a industrialização emerge como eixo central da estratégia cepalina, pois "[...]além de contribuir para a absorção da população que cresce e se desloca de outras atividades, proporciona ao país em desenvolvimento os produtos manufaturados que ele não pode conseguir, dada a sua capacidade limitada de importar" (Prebisch, 2000, p. 189).

Modelos de crescimento liderado pela demanda e limitado pelo BP (denominado BPC - Balance of Payments Constrained Growth) têm sido desenvolvidos, em versões mais contemporâneas, a partir das contribuições de Thirlwall.

A versão apresentada em Thirlwall (1979) mostrou que a taxa de crescimento de longo prazo compatível com a restrição do BP é dada pela razão entre a taxa de crescimento das exportações (ou elasticidade-renda das exportações multiplicada pelo crescimento mundial) e a elasticidade-renda das importações; resultado conhecido como Lei de Thirlwall ${ }^{3}$. Essa dinâmica somente faz sentido quando o equilíbrio de longo prazo no balanço de pagamentos - nessa versão, sem fluxos de capitais - é um requisito, questão que será discutida em seguida.

Para McCombie e Thirlwall (1994) e Thirlwall (2005), o desempenho das exportações depende conjunturalmente do crescimento da renda mundial e estruturalmente da competitividade da indústria, a qual determina, em grande parte, os termos de troca entre os países. Os autores destacam a importância da industrialização como motor do crescimento, pois o setor industrial opera com retornos crescentes de escala e é difusor de inovações, influenciando a produtividade de toda a economia, aumentando assim sua competitividade (penetração) no mercado externo. O dinamismo industrial, ao provocar aumento de produtividade nos demais setores, melhora as condições de competitividade e os termos de troca o que, por sua vez, se reflete na melhora da conta de transações correntes, reduzindo a restrição externa.

As taxas de crescimento previstas pelo modelo de Thirlwall (1979) ficaram bem próximas das taxas de crescimento observadas nos países desenvolvidos utilizados em sua amostra. No entanto, Thirlwall e Hussain (1982) observaram que o poder explicativo do modelo era menor quando se analisavam países em

(3) Segundo Thirlwall, a realização de correlações seriais entre a taxa efetiva de crescimento e a prevista pela condição de equilíbrio no BP garantiram e reforçaram o seu achado teórico, pois "quase se poderia afirmar como lei fundamental que a taxa de crescimento de um país se aproximará da proporção de sua taxa de crescimento das exportações e de sua elasticidade-renda da demanda de importações [...] desde então, esse resultado passou a ser conhecido na literatura especializada como lei de Thirlwall [...], um previsor poderoso do desempenho dos países tem termos de crescimento" (Thirlwall, 2005, p. 65). 
desenvolvimento. A fim de contemplar a experiência de países em desenvolvimento, os autores estenderam o modelo original incorporando a conta de capital na definição da condição de equilíbrio do BP, já que para países em desenvolvimento os fluxos de capitais constituem uma fonte relevante de financiamento de déficits em transações correntes. Nesse modelo ampliado, a condição de equilíbrio de longo prazo passa a incorporar a conta de capital, sendo definida como $P_{d t} X_{t}+C_{t}=P_{f t} E_{t} M_{t}$, em que $C_{t}$ é o valor nominal dos fluxos de capital medidos em moeda nacional. Em termos de taxa de crescimento, a condição de equilíbrio pode ser expressa por: $\theta\left(p_{a t}+x_{t}\right)+(1-\theta) c_{t}=p_{f t}+e_{t}+m_{t}^{4}$, em que $c_{t}$ é a taxa de crescimento dos fluxos de capitais nominais, $\theta$ é a parcela das exportações em relação à receita externa total $\left(P_{d t} X_{t}+C_{t}\right)$ para custear as importações e $1-\theta$ é a proporção dos fluxos de capital em relação à receita externa total. A partir dessa condição de equilíbrio do BP e das mesmas funções comportamentais de demanda para as exportações e importações do modelo canônico, Thirlwall e Hussain (1982) apresentaram a taxa de crescimento do produto compatibilizada com o equilíbrio do $\mathrm{BP}^{5}$.

Em linhas gerais, na versão modificada por Thirlwall e Hussain (1982), a taxa de crescimento permitida pelo equilíbrio de BP é dada pela soma ponderada da taxa de crescimento das exportações com a taxa de crescimento da entrada líquida de capitais, dividida pela elasticidade-renda das importações. Assim, a taxa de crescimento consistente com o equilíbrio no BP de longo prazo é aquela em que o saldo do BP seja zero no longo prazo, mesmo que isso implique desequilíbrios persistentes na conta corrente.

Neste artigo, considera-se que o modelo estendido de Thirlwall e Hussain contempla apenas parcialmente a problemática associada aos movimentos de capitais, já que não incorpora o montante de pagamentos associados ao crescimento do passivo externo (juros, remessa de lucros, repatriação etc.), e nem mesmo a percepção e reação dos agentes caso o passivo externo aumente além de

(4) Esta equação de equilíbrio externo, em termos de taxa, foi derivada da seguinte equação em termos de nível: $P_{d t} X_{t}+C_{t}=P_{f t} E_{t} M_{t}$. em que $P_{d t}$ é o preço das exportações em moeda local; $X_{t}$ é a quantidade exportada; $C_{t}$ é o valor do fluxo de capital em moeda doméstica, sendo que se $C_{t}>0$ está ocorrendo uma entrada de capital e se $C_{t}<0$ verifica-se uma saída de capital; $P_{f t}$ é o preço das importações em moeda estrangeira; $E_{t}$ é a taxa de câmbio nominal; $M_{t}$ é a quantidade importada; e t representa o tempo. No entanto, conforme alertam os autores, é preciso dar pesos aos componentes do lado esquerdo da equação, de modo que $\theta$ e (1- $\theta$ ) representam as participações relativas das exportações e dos fluxos de capitais no financiamento das importações.

(5) Supondo que as elasticidades-preço cruzadas das exportações e das importações são iguais às suas respectivas elasticidades-preço, a condição de equilíbrio do BP com fluxos de capital se dá por: $y_{b y}=\frac{\left(p_{\Delta}-p_{A}-e_{i}\right)+(\theta \eta+\psi)\left(p_{\Delta}-p_{A}-e_{i}\right)+\theta z_{i}+(1-\theta)\left(c_{i}-p_{\Delta}\right)}{\pi}$ 
determinados patamares, o que foi ao menos parcialmente contemplado pelo modelo desenvolvido por Moreno-Brid (1998).

A entrada de capital, tanto via empréstimos como por meio de fluxos voluntários de capital, gera sempre, em algum grau, a possibilidade de refluxo desse capital, seja pelo seu retorno (especialmente quando se trata de capital de curto prazo), seja pela remessa de lucros ou pagamento de juros. Logo, o "teto" para os fluxos deve ser dado pela exigência de equilíbrio no BP no longo prazo ditado pelas condições de solvência da economia e de seus possíveis efeitos decorrentes da reação dos agentes diante do agravamento dos indicadores de vulnerabilidade.

Moreno-Brid chama a atenção para o fato de que poderão existir restrições à entrada de capital, especialmente se o padrão de endividamento não for sustentável do ponto de vista do investidor externo. Como resultado se teria saídas de capital e/ou uma suspensão na entrada, o que geraria restrições. A proposta aventada pelo autor para corrigir a carência do modelo de Thirlwall e Hussain (1982) foi incluir um indicador de grau aceitável de endividamento, de modo que o equilíbrio do BP requereria a manutenção de uma razão constante entre o saldo em transações correntes e a renda doméstica, de maneira a garantir que o grau de endividamento externo fosse constante ${ }^{6}$.

Em uma tentativa de dar mais realismo à questão dos fluxos de capitais, o modelo proposto nesse artigo irá incorporar a reação dos agentes - repatriando capital e interrompendo a entrada - diante da piora do passivo externo em relação às exportações. Diferentemente de Moreno-Brid, considerou-se um indicador de piora nas condições externas em relação à real capacidade de cumprir com o passivo externo, o desempenho exportador. O que será explicado na próxima seção ${ }^{7}$.

\section{Um modelo macro-multissetorial: análise do crescimento para economias abertas}

O modelo macroeconômico-multissetorial aqui proposto é essencialmente um modelo de crescimento liderado pela demanda e restrito pelas condições externas, integrando as discussões feitas na seção anterior e que, em sua essência, podem ser assim resumidos: i) o PDE keynesiano e kaleckiano; e ii) o papel que a restrição externa exerce como um dos mais relevantes empecilhos ao crescimento da demanda. No entanto, consideramos a possibilidade de incorporar duas das críticas feitas ao modelo canônico de Thirlwall, quais sejam: (i) daremos um tratamento mais

(6) Além de Moreno-Brid (op. cit.), a problemática associada ao acúmulo do passivo externo foi explorada por diversos autores tais como Barbosa-Filho $(2001,2002)$

(7) Sobre o tema, ver também Barbosa-Filho (2002) e para um survey de indicadores das condições externas ver Kaminsky et. al. (1998). 
detalhado à relevância dos fluxos de capitais e aos processos a eles associados; e (ii) os coeficientes de importação e de exportação de bens de consumo e de insumos serão sensíveis a variações da renda (interna e externa), aos preços relativos e à taxa de câmbio.

O modelo é multissetorial e os setores produtivos são classificados ${ }^{8}$ em oito agrupamentos: setores de bens de consumo (duráveis ${ }^{9}$ e não duráveis ${ }^{10}$ ), setores de bens intermediários (metalúrgicos ${ }^{11}$, químicos ${ }^{12}$ e outros ${ }^{13}$ ), setor de bens de capital $^{14}$, agricultura ${ }^{15}$ e serviços ${ }^{16}$. Os oito setores são "agentes" desse modelo, que conta ainda com: i) consumidores agrupados em quatro classes de renda (A, B, C e D); ii) o governo; e iii) o setor externo ${ }^{17}$.

O modelo tem como unidade de referência o período de produção: um ano estilizado possui quatro períodos de produção. Seis períodos de produção correspondem a um período de investimento (um ano e meio). Essa distinção entre as decisões de investir e de produzir busca refletir o fato de que os eventos econômicos ocorrem com temporalidade distinta ${ }^{18}$. A seguir se apresentam os blocos do modelo ${ }^{19}$ :

(8) Utilizando a metodologia do IBGE.

(9) Conforme IBGE: fabricação de aparelhos e equipamentos de material eletrônico; fabricação de automóveis, caminhões e ônibus; fabricação de outros veículos, peças e acessórios.

(10) Fabricação de produtos farmacêuticos e de perfumaria; indústria têxtil; fabricação de artigos de vestuário e acessórios; fabricação de calçados e de artigos de couro e peles; indústria do café; beneficiamento de produtos de origem vegetal, inclusive fumo; abate e preparação de carnes; resfriamento e preparação do leite e laticínios; indústria do açúcar; fabricação e refino de óleos vegetais e de gorduras para alimentação; outras indústrias alimentares e de bebidas; indústrias diversas.

(11) Extrativa mineral (exceto combustíveis); siderurgia; metalurgia dos não ferrosos e outros produtos metalúrgicos.

(12) Extração de petróleo e gás natural, carvão e outros combustíveis; fabricação de elementos químicos não petroquímicos; refino de petróleo e indústria petroquímica; fabricação de produtos químicos diversos; indústria de transformação de material plástico.

(13) Fabricação de minerais não metálicos; serrarias e fabricação de artigos de madeira e mobiliário; indústria de papel e gráfica; indústria da borracha.

(14) Fabricação e manutenção de máquinas e tratores; fabricação de aparelhos e equipamentos de material elétrico; construção civil.

(15) Agropecuária. Do setor agrícola são demandados insumos e bens de consumo não duráveis.

(16) Serviços industriais de utilidade pública; comércio; transporte; comunicação; instituições financeiras; serviços prestados às famílias; serviços prestados às empresas; aluguel de imóveis; administração pública; serviços privados não mercantis.

(17) Os setores recebem encomendas dos demais setores, das classes de renda, do governo e do setor externo, sendo que eles não são integrados verticalmente, de modo que cada setor não demanda de si mesmo, com exceção do setor agrícola e dos de bens intermediários.

(18) Uma discussão metodológica sobre as instâncias do tempo econômico ver em Possas (1987, p. 54 e seg.).

(19) Todas as relações são expressas por equações. Apresentaremos apenas as essenciais para compreensão do argumento. Para uma referência completa ver Busato (2012). 


\subsection{Produção programada}

A produção programada (PPG) de cada setor no início de cada período de produção $\left(x_{i, t}^{p p}\right)$ é função de expectativas extrapolativas ${ }^{20}$ de vendas para o período $\left(x^{v p}{ }_{i, t}\right)^{21}$. Em sua PPG os setores levarão em conta a margem de estoque desejado ( $\left.\sigma_{i}\right)^{22}$; a disponibilidade de insumos; e a capacidade produtiva $\left(\bar{x}_{i, t-1}\right)^{23}$. A PPG é definida: $x_{i, t}^{p p}=x_{i, t}^{v p} \times\left(1+\sigma_{i}\right)-x_{i, t-1}^{s}$; sujeito a: $0 \leq x^{p p}{ }_{i, t} \leq \beta_{i} * \bar{x}_{i, t-1}$. Ou seja, a PPG é função das vendas previstas adicionada da margem de estoque desejado, deduzido do estoque do período anterior, $x^{s}{ }_{i, t-1}$, sujeito à restrição de capacidade produtiva e uma margem $\beta_{i}$ de sobreutilização. Após definir a PPG e dados os coeficientes técnicos de insumos nacionais e importados, os setores demandam insumos necessários para realizar o processo produtivo. Ou seja, a demanda por insumos é feita no período corrente para realizar a PPG no período seguinte.

\subsection{Demanda por bens intermediários}

A quantidade necessária de insumos é função da PPG e dos coeficientes técnicos de insumo nacional e importado e pode ser expressa por: $x_{i, j, t}^{i n}=x_{i, t}^{p p} \times\left(a_{i, j, t}+a_{i, j, t}^{m}\right)$. A soma dos coeficientes técnicos é determinada pela estrutura produtiva e pela relação capital/produto. Entretanto, a distribuição entre o uso de insumos nacionais e importados poderá se alterar em resposta a variações na renda interna e aos preços relativos, conforme será explicitado no bloco do setor externo. No início de cada período, o setor confronta novamente a PPG com o estoque disponível de insumos. Caso se verifique que o estoque disponível de insumos não seja insuficiente para realizar sua PPG, faz-se uma demanda extra por insumos (que poderá ser atendida caso os setores de bens intermediários tenham

(20) Expectativas calculadas a partir da média das encomendas efetivas passadas. Ou seja, "o resultado realizado acaba mudando as expectativas subsequentes" (Keynes, 1997, p. 47). O fator de projeção das expectativas, $\gamma_{i, t}$, busca captar o grau de confiança dos agentes em suas próprias expectativas; é endógeno e varia em função do indicador de risco de insolvência do país.

(21) As vendas previstas são calculadas com base nas encomendas efetivas passadas e projetadas de acordo com o fator $\gamma_{i, t}: x^{v p}{ }_{i, t}=\lambda_{i, t}^{E x p} \times \frac{x_{i, t-1}^{e}+x^{e}{ }_{i, t-2}}{2} \times\left[1+\gamma_{i, t} \times \frac{\left(x_{i, t-1}^{e}+x_{i, t-2}^{e}\right)-\left(x_{i, t-3}^{e}+x_{i, t-4}^{e}\right)}{\left(x_{i, t-3}^{e}+x_{i, t-4}^{e}\right)}\right]$.

(22) A margem desejada de estoque é tratada como parâmetro. Este e outros parâmetros do modelo são estabelecidos por "educated guess" ou, no caso de ausência de dados empíricos sobre o parâmetro, seus valores serão testados de acordo com o método de calibração indireta.

(23) A produção dos setores pode ser limitada pela capacidade produtiva, considerando uma margem de sobreutilização. 
estoques). Esse procedimento visa dar uma margem de ajuste em relação às expectativas que originaram a demanda por insumos no período anterior ${ }^{24}$.

\subsection{Investimento}

O investimento visa (i) repor capital depreciado; (ii) ajustar a capacidade produtiva de acordo com as expectativas de venda e com o grau de utilização desejado da capacidade ${ }^{25}$; e (iii) fazer frente à concorrência e a oportunidades, componente em grande medida autônomo. Segue uma lógica keynesiana-kaleckiana, visto que é induzido pelo grau de utilização, mas está multiplicado O investimento induzido $\left(\Delta x_{i, t}^{-d}\right.$ ) leva em conta: 1) as vendas previstas para os próximos seis períodos de produção (= período de investimento) após a entrega dos bens de capital $\left(x_{i, t}^{e e}\right)$.As vendas previstas são calculadas com base nas encomendas efetivas passadas, portanto, o investimento é induzido pela taxa de crescimento esperada que é função das encomendas efetivas passadas. Logo, as expectativas de crescimento dizem respeito à taxa de crescimento das EEF e não ao nível de EEF. A projeção

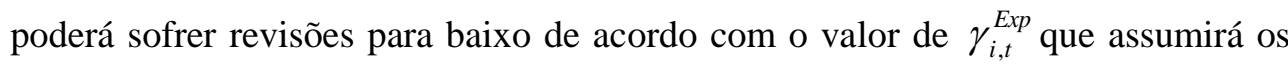
valores $\{1.0 ; 0.93 ; 0.91 ; 0.89\}$, ou seja, à medida que o indicador de insolvência aumenta, os agentes projetam para o futuro apenas parte do que ocorreu no passado. Essa é uma maneira tipicamente keynesiana de formular expectativas, de modo que os agentes projetam o passado em condições 'normais', mas revisam o modo de formular expectativas se acreditam haver motivos/circunstâncias que justifiquem; 2) a reposição do capital depreciado de acordo com a taxa de depreciação $\delta_{i}$ que incidirá sobre o estoque de capital $\left.\left(\bar{x}_{i, t}\right) ; 3\right)$ os erros de previsão cometidos no passado; 4) a margem de estoque $\sigma_{i}$ desejada; e 5) o grau de utilização desejado da capacidade $\left(\alpha_{i}\right) . \quad \mathrm{O}$ investimento pode ser expresso por: $\Delta x_{i, t}^{-d}=\left[x_{i, t}^{e e} \times\left(\frac{1+\sigma_{i}}{\alpha_{i}}\right)-\bar{x}_{i, t} \times\left(1-\delta_{i}\right)\right]$.

Além do investimento induzido, os setores realizam a cada período de investimento um gasto autônomo em investimento que se vincula à dinâmica concorrencial inovativa. $\mathrm{O}$ investimento autônomo em parte substitui capital depreciado por obsolescência e nessa medida não amplia capacidade produtiva, mas permite que se produzam produtos de qualidade superior ou com menor custo, o que

(24) Os setores de bens intermediários - exceto o agrícola - têm uma particularidade, pois eles não conhecem seus estoques ex ante, já que poderão atender à demanda extra de insumos no início do período. Desse modo, sua demanda de insumos é dada em função das encomendas efetivas recebidas de insumos dos demais setores com uma margem de extrapolação.

(25) Uma decisão essencialmente kaleckiana, de acordo com o princípio do ajustamento do estoque de capital. 
implica na melhoria da competitividade média dos setores. O investimento autônomo ${ }^{26}$ é definido como uma proporção constante do estoque de capital de cada setor.

O governo tem uma demanda por investimento determinada pelo coeficiente de investimento do governo multiplicado pelos seus gastos totais.

$\mathrm{O}$ modelo incorpora uma restrição financeira ao investimento. $\mathrm{O}$ acesso ao crédito é ditado pelo capital próprio acumulado pela firma (lucro retido), ou seja, de acordo com o "princípio do risco crescente", a dimensão do capital empresarial e a acumulação de capital funcionam como uma limitação do acesso ao crédito. $\mathrm{O}$ financiamento do investimento desejado (induzido e autônomo) conta com três fontes: 1) a participação estrangeira por meio de fluxos de IDE; 2) recursos próprios dos setores; e 3) recursos de terceiros (empréstimos obtidos tanto no Sistema Financeiro Nacional (SFN) como no Sistema Financeiro Internacional (SFI $\left.{ }^{27}\right)$. A discussão sobre restrição ao financiamento será detalhada mais à frente ${ }^{28}$.

\subsection{Demanda por bens de consumo}

A demanda que os setores produtores de bens de consumo recebem se resume em procura interna - das famílias e do governo - e naquela proveniente do exterior (exportação), que será apresentada no bloco do setor externo. No que diz respeito às famílias, a demanda por bens de consumo de cada uma das quatro classes de renda é calculada multiplicando-se a renda real média, determinada em função da defasagem considerada ${ }^{29}$, pela respectiva propensão a consumir - decrescente com a renda média de cada faixa, somando-se a isso o consumo autônomo ${ }^{30}$. A demanda por bens de consumo do governo é obtida multiplicando os gastos totais do governo pela proporção dos gastos destinados a consumo.

\subsection{Produção efetiva, vendas observadas e demanda atendida}

A produção efetiva, realizada de acordo com as vendas esperadas, poderá ou não coincidir com a demanda efetiva total (dos setores, das classes de renda e do governo). Como o modelo é dinâmico, as expectativas de curto prazo sofrem ajustes após a confrontação entre a oferta (ex ante) e a demanda (ex post). Se as expectativas

(26) O investimento autônomo é mantido como uma proporção constante do estoque de capital de cada um dos setores: $x^{k a d}{ }_{i, t}=k a_{i} \times \bar{x}_{i, t}$, seguindo sugestão de Kalecki ([1954] 1983, cap. 14), para o investimento agregado.

(27) Dos recursos tomados de terceiros, vinte por cento são tomados no mercado internacional.

(28) Se houver escassez de recursos para financiar todo o investimento desejado, impõe-se uma ordem de prioridade: $1^{\circ}$ se executa a reposição da capacidade depreciada; $2^{\circ}$ investimento que visa a ampliação da capacidade; e por último o investimento autônomo.

(29) Classe A, defasagem de 4 períodos; 3 períodos para a classe $\mathrm{B} ; 3$ para a classe C; e 1 para a D.

(30) A disponibilidade de recursos para consumo autônomo depende do grau de endividamento das classes. 
formuladas não se confirmam, o erro provoca acúmulo de estoques indesejados e as expectativas sofrem ajustes, o mesmo ocorrendo com a decisão de produção subsequente, com consequências sobre a dinâmica da economia.

\subsection{Preço e renda}

Os preços são fixados seguindo a tradição kaleckiana de regra de markup sobre os custos variáveis unitários de produção (salários e insumos). O setor agrícola segue uma lógica mais concorrencial e os preços de seus produtos exportáveis são determinados pelo mercado internacional.

A receita líquida de vendas setorial é obtida pela multiplicação do preço de venda cobrado pelas vendas realizadas no período, o que equivale à receita bruta da produção descontados os impostos indiretos que incidem sobre as vendas; e as despesas totais de produção dos setores se resumem em gastos com pagamento de salários e com matéria prima. Os primeiros, determinados de forma paramétrica, pela multiplicação do que foi produzido pelo salário unitário; os gastos com matéria prima são divididos entre despesas com insumos importados e com insumos nacionais.

Os insumos adquiridos no período corrente para viabilizar a produção no período seguinte serão financiados por capital de giro. $\mathrm{O}$ fluxo de capital de giro no período é a diferença entre os gastos totais com insumos e o pagamento realizado com recursos próprios. Esse fluxo acresce o estoque de capital de giro existente no período anterior, sobre os quais os setores pagaram juros, os quais compõem receita para o setor de serviços. Nas despesas do setor de serviços se computa o retorno sobre a aplicação financeira das classes, dos setores e sobre o investimento externo em carteira.

O lucro bruto do setor é computado pela diferença entre receitas e as despesas. O lucro total da economia é obtido pelo somatório do lucro dos setores; e o salário total da economia é obtido pela soma dos salários pagos pelo governo e pelos setores. Dos gastos totais do governo, se supõe que uma proporção fixa se refere a gastos com pagamento de salários.

O somatório do salário total, lucro total e dos impostos indiretos nos dará o valor do PIB sob a ótica da apropriação da renda: $Y_{t}=y^{L}{ }_{t}+y^{W}{ }_{t}+y^{\tau^{i}}{ }^{i}$.

\subsection{Governo}

As atividades principais do governo são: arrecadação de impostos (diretos e indiretos), gastos (com pessoal, consumo e investimento), intervenção na economia com metas implícitas de câmbio, de superávit e determinação da taxa de juros. Não há uma regra reativa de juros no modelo. O governo gasta com consumo, 
investimento e pagamento de salários. A proporção dos gastos para cada um dos destinos é fixa, aplicadas sobre o montante de recursos de que o governo dispõe para gastar. Estes são determinados de acordo com a meta de superávit primário, o que os torna endógenos. A meta de superávit é estipulada e recalculada a cada quatro períodos de produção ("anualmente"), limitada por teto e piso. A meta poderá variar de acordo com dois critérios: a relação dívida pública/PIB; e as taxas anuais de crescimento de ambos. Se a razão dívida/PIB for inferior a 30\%, a meta cairá em um percentual definido pelo estabilizador automático da relação dívida/PIB, $\Omega$, ou seja, $\mu_{t}=\mu_{t-1}(1-\Omega)$. Se a razão dívida/PIB estiver entre $30 \%$ e $60 \%$ e o PIB crescer mais que a dívida, a meta também cairá na proporção $\Omega$, caso contrário, a meta anual não muda, $\mu_{t}=\mu_{t-1}$. Já se a razão dívida/PIB superar $60 \%$, a meta aumentará na proporção do estabilizador automático.

O superávit alvo é a meta de superávit em termos monetários ${ }^{31}$ : o produto da meta de superávit pelo PIB do último período, adicionada uma taxa de projeção do crescimento do PIB que é calculada utilizando expectativas da taxa de crescimento médio dos últimos dois períodos em relação aos dois imediatamente anteriores. $\mathrm{O}$ peso dado às expectativas é função do grau de confiança do governo em suas expectativas.

O total de que o governo dispõe para gastar é dado pela diferença entre a arrecadação esperada de impostos e o superávit alvo. A receita total de impostos é resultado da soma dos impostos diretos e indiretos. Os impostos diretos incidem sobre a renda (lucro ${ }^{32}$ e renda salarial das classes $^{33}$ ) e sobre o retorno das aplicações financeiras. Já os impostos indiretos incidem sobre a receita bruta dos setores.

O superávit primário é a diferença entre o total de impostos arrecadados e o total de gastos públicos realizados. Além das despesas correntes, o governo pagará juros sobre seus estoques de dívidas interna ${ }^{34}$ e externa ${ }^{35}$. O déficit público nominal é a diferença entre pagamento de juros e superávit primário.

\subsection{Setor externo e a restrição}

O bloco do setor externo é central para este artigo, visando captar as contribuições mais relevantes sobre o tema, descritas na seção anterior, bem como contribuições relativas à dinâmica dos fluxos de capitais e às condições de solvência

(31) $\mu_{t-1} \times Y_{t-1} \times\left[1+\gamma_{G} \times \frac{\left(Y_{t-1}+Y_{t-2}\right)-\left(Y_{t-3}+Y_{t-4}\right)}{\left(Y_{t-3}+Y_{t-4}\right)}\right]$

(32) Alíquota de $20 \%$ para todos os setores.

(33) A alíquota de $25 \%$ classe A, $15 \%$ para a classe B e zero para as classes C e D.

(34) O estoque de dívida interna, $\left({ }^{D P i} y_{t}^{G}\right)$ é igual ao estoque da dívida somado ao déficit público corrente.

(35) Como o governo não emite ou esteriliza moeda, o saldo do BP, a amortização da dívida externa e os empréstimos contraídos no exterior implicam a variação da dívida pública interna. 
externa. Os coeficientes de importação e de exportação de bens de consumo e de insumos foram considerados sensíveis à variação na renda (interna e externa), aos preços relativos e à taxa de câmbio.

\section{Transações correntes}

O cálculo do saldo da conta de transações corrente (TC) e o saldo da balança comercial (BC) seguem o padrão do BP do Banco Central do Brasil. A demanda por exportações destinadas aos setores nacionais é calculada pela aplicação do coeficiente de exportação setorial $\left(\chi_{i, t}\right)$ sobre a renda externa, dividida pelo preço dos bens nacionais, para transformar o valor em unidades de produto. A renda mundial cresce por hipótese a uma taxa constante $(\dot{x})$.

O coeficiente de exportação foi endogeneizado a fim de captar o efeito das mudanças nos preços relativos, do crescimento da renda mundial e do impacto que o investimento autônomo produz sobre a competitividade dos bens exportáveis. Setores com maior concorrência não preço têm seus coeficientes de exportação mais sensíveis a alterações no investimento autônomo; já setores com maior concorrência via preço têm os coeficientes de exportação mais sensíveis a mudanças nos preços relativos. Buscou-se retratar a relevância dos termos de troca de alterações na renda externa sobre o coeficiente de exportação a fim de captar as contribuições de Ferrari, Freitas, Barbosa-Filho (2010); Gala (2006); entre outros, que argumentaram que a elasticidade-preço muda em resposta à persistência de um nível cambial valorizado ou desvalorizado. Incorporamos o argumento, mas fizemos o coeficiente de exportação sensível à variação da taxa de câmbio e não ao seu nível ${ }^{36}$. Com isso, o coeficiente de exportação varia em função do crescimento da renda externa, dos preços relativos dos bens nacionais e internacionais e do impacto do investimento autônomo sobre a competitividade dos bens produzidos no país. A participação das exportações nas vendas totais foi calculada usando por aproximação a metodologia utilizada pela Fiesp ${ }^{37}$. Assim, pode-se construir um indicador que mostra a participação das vendas setoriais para o exterior (exportação setorial) nas vendas totais setoriais.

O total importado se resume à soma da importação de bens de consumo, de insumos necessários à produção e de bens de capital. A demanda por importação é definida de maneira análoga à demanda interna. A propensão a consumir das classes é um parâmetro, mas a distribuição entre propensão a consumir bens nacionais e importados é função da variação da renda doméstica, dos preços relativos e de suas

(36) Existe um debate sobre a influência do nível e/ou da taxa de câmbio sobre os coeficientes de exportação. Utilizou-se taxa para evitar uma discussão sobre qual seria o nível de 'equilíbrio' da taxa de câmbio para a indústria.

(37) Cf. Fiesp (2009). 
respectivas sensibilidades. A importação de insumos é função do coeficiente técnico de importação e da extrapolação para o período seguinte da produção programada do setor. O coeficiente técnico de importação de insumos é determinado a partir de seu valor no último período, da variação nas encomendas efetivas recebidas pelo setor e da relação entre os preços dos insumos nacionais e importados.

A importação total dos bens de capital é definida a partir da multiplicação da demanda por bens de capital pelo coeficiente de importação. O valor agregado monetário das importações da economia é obtido pela soma dos produtos das quantidades importadas de insumos, bens de consumo e bens de capital pelos respectivos preços internacionais.

\section{Saldo da balança de serviços}

A conta de serviço de fatores ${ }^{38}$ é composta pelo lucro reinvestido ${ }^{39}$ e pela remessa de lucros e de juros.

O total dos lucros reinvestidos na economia é igual à soma dos lucros reinvestidos por cada setor. $\mathrm{O}$ lucro relativo à participação estrangeira é uma parcela do lucro distribuído pelos setores. Da participação estrangeira uma parte será reinvestida no país. A parcela de reinvestimento dependerá do indicador de risco de insolvência (IRI). Se o IRI for inferior ao valor padrão mínimo ${ }^{40}$, o reinvestimento atinge seu máximo e será igual a $50 \%$ da participação estrangeira do lucro; se o indicador estiver entre o padrão mínimo e o máximo, sinalizando que há risco efetivo de insolvência, o reinvestimento cai para 20\%; e se o indicador for maior que o padrão máximo aceitável, haverá um reinvestimento do lucro da ordem de apenas $10 \%$. Logo, o coeficiente de reinvestimento, $\varepsilon_{i}^{r l}$ assumirá os valores $\{0,1 ; 0,2 ; 0,5\}$. Assim sendo, o total dos lucros reinvestidos pode ser escrito da seguinte forma: ${ }^{l k} y_{t}^{E}=\sum_{i}\left(y_{i, t}^{-l r} \times\left(1-\tau_{i}^{d}\right) \times\left(1-\varphi_{i}\right) \times \varepsilon_{i, t-1}^{P E} \times \varepsilon_{i}^{r l}\right)$.

O complemento do reinvestimento é a remessa de lucros para o exterior, que aumenta de acordo com a piora do IRI. Se o coeficiente de reinvestimento assumir

(38) Por simplificação, está sendo considerado que o país não tem capital no exterior que gere entrada de juros, lucros ou dividendos.

(39) De acordo com a nova metodologia de apuração adotada pelo Banco Central do Brasil e seguindo a metodologia da quinta edição do Manual de BP do Fundo Monetário Internacional, o lucro reinvestido deve ser contabilizado com sinal negativo no balanço de serviços e rendas e com sinal positivo na conta financeira (aumentando o estoque de IDE). Diferente da maioria dos PLAs, o BC do Brasil não divulga esse dado sob o argumento de que ele não altera o fluxo de divisas e não há estímulos para que as empresas forneçam corretamente tal informação. Isso significa que o passivo externo brasileiro fica subestimado. No modelo adotaremos o mesmo critério recomendado pelo FMI.

(40) $I_{2} I_{t} \leq 8,0 \Rightarrow$ Baixo_risco; $10,5>I R I_{t}>8,0 \Rightarrow$ Médio_risco; $I R I_{t} \geq 10,5 \Rightarrow$ Alto_risco 
os valores de 0,$1 ; 0,2$ e 0,5 , a proporção do lucro remetida ao exterior será, respectivamente, de 0,$9 ; 0,8$ e 0,5 .

O total do pagamento de juros que é remetido ao exterior é dado pelo pagamento de juros sobre os empréstimos e financiamentos contraídos pelo governo e pelos setores, somados à remuneração do estoque de investimento estrangeiro em carteira aplicado no país.

\section{Conta de capital e financeira}

A conta de capital e financeira registra os fluxos financeiros e é composta por quatro contas: 1) entrada de investimento direto estrangeiro - IDE; 2) movimento de investimento em carteira; 3) empréstimos e financiamentos, contraídos pelo governo e pelos setores; e 4) amortizações: $y^{C C}{ }_{t}=y_{t}^{\varepsilon}+{ }^{c p} y_{t}+{ }^{n d e} y_{t}^{G}+{ }^{n d} y_{t}^{E}-{ }^{A} y_{t}^{E}$.

\section{IDE - Investimento direto estrangeiro}

Cada setor possui um percentual do estoque de capital como participação estrangeira, já que do investimento desejado pelos setores uma parcela sempre será coberta com recursos de IDE. Diante da piora do cenário externo, o fluxo de IDE se reduz gradativamente. Se o IRI estiver abaixo do limite padrão mínimo, haverá disponibilidade de recursos de IDE igual à participação do capital estrangeiro padrão setorial multiplicado pelo investimento desejado. Se o IRI estiver entre o mínimo e o máximo, começa a haver inquietude e os recursos de IDE passam a ser de apenas $40 \%$ da participação estrangeira padrão. Se o indicador está acima do valor padrão máximo, os recursos de IDE estarão disponíveis em apenas $20 \%$ da participação padrão.

\section{Investimento em carteira}

O movimento de capital especulativo em carteira é determinado a partir de um valor de referência ${ }^{41}$ e é motivado pelo diferencial entre juros internos e externos, pelo risco-país e pela expectativa de desvalorização cambial. Além disso, se o IRI superar o limite aceitável, haverá saída de uma parcela, $\varepsilon^{c p}$, do estoque do investimento em carteira. Se o IRI é inferior ao valor padrão mínimo, $\varepsilon^{c p}=0$ e não há saídas motivadas pelo risco de insolvência. Se o indicador estiver entre o padrão mínimo e máximo, $\varepsilon^{c p}=0,03$, implicando que haverá uma saída de $3 \%$ do estoque de capital durante o tempo em que o indicador de insolvência permanecer neste patamar. Se o IRI assumir valores superiores àquele máximo, haverá saída de $8 \%$ do estoque.

(41) Determinado pela liquidez internacional. 


\section{Empréstimos de regulação}

Além dos movimentos autônomos de capitais, a conta de capital e financeira poderá englobar ainda os empréstimos ao governo que incorporam as operações de regulação decorrentes da apuração do saldo do BP, do saldo das reservas e da meta de reservas do governo. Após apurado o saldo do BP, poderá ainda haver movimento de capitais compensatórios caso o volume de reservas apurados após o 'préfechamento' do BP seja inferior à meta estabelecida pelo governo. Nesse caso, o governo tomará empréstimos, alterando o saldo de conta de capital, bem como o do BP. Na prática isso ocorre da seguinte forma: apura-se o saldo da conta de capital "pré" (para verificar a necessidade de tomada de empréstimos compensatórios), soma-se a esta o saldo em reservas acumuladas no último período, obtendo-se assim o saldo de reservas no período corrente, e subtrai-se a meta de reservas. Se o valor for positivo, não haverá necessidade de empréstimos compensatórios; caso seja negativo, este será o valor da tomada do empréstimo pelo governo, aumentando assim o saldo da balança de capital e financeira e, consequentemente, o saldo do BP, trazendo as reservas para a meta estabelecida.

\section{Saldos, estoques e demais indicadores}

\section{Passivo externo, taxa de câmbio e meta de reservas}

O passivo externo líquido é igual ao passivo externo descontadas as reservas; já o passivo externo de curto prazo é composto pelo estoque de investimento estrangeiro aplicado no setor financeiro nacional. O passivo externo do país é dado pela soma do estoque de IDE, de IE em carteira e dos empréstimos contraídos pelo Governo e pelo setor privado nacional.

O governo possui uma meta de reservas que é calculada visando uma razão "segura" entre o total das reservas e o passivo externo de curto prazo. A taxa de câmbio é flexível, porém varia dentro de bandas implícitas estipuladas pelo governo, que dão um teto e um piso para a taxa de câmbio a partir de um valor de referência ${ }^{42}$.

\section{Expectativas}

Além de influenciar os fluxos de IDE, o investimento em carteira, o reinvestimento e a remessa de lucros, o IRI afeta também o grau de confiança nas expectativas e o próprio padrão de formação das mesmas. Ambas terão influência sobre as decisões de produzir e de investir. O grau de confiança é dado por: $\gamma_{i, t}=\varepsilon_{t}^{g c} \times \bar{\gamma}_{i}$ e, como visto no bloco de produção e no de investimento, $\gamma_{i, t}$ é o fator que busca captar o grau de confiança dos agentes em suas próprias expectativas. $\mathrm{O}$ primeiro termo à direita da igualdade mostra a sensibilidade do fator de projeção

(42) Na apresentação dos resultados denominaremos por 'taxa de câmbio pré' a taxa de câmbio que vigoraria se o regime cambial fosse flexível. 
ao IRI e assumirá, em ordem crescente de risco, os valores: $\varepsilon_{t}^{g c}=\{1,0 ; 0,17 ; 0,1$; $0,0\}$, e o segundo termo à direita mostra o fator de projeção padrão das expectativas que vigora em 'condições normais', $\bar{\gamma}_{i}$.

Já as expectativas 'tipicamente keynesianas', $\gamma_{i, t}^{E x p}$, são assim determinadas: $\gamma_{i, t}^{E x p}=\varepsilon_{t}^{K e y} \times \bar{\gamma}_{i}^{E x p}$. O primeiro termo da direita da igualdade mostra a sensibilidade das expectativas ao indicador de solvência e assumirá os valores $(1 ; 0,93 ; 0,91 ; 0,89)$ de acordo com o que ocorre com o IRI. Enquanto o IRI permanecer abaixo de oito $(8,0)$ - valor de referência a partir do qual os agentes reagem -, o valor do coeficiente $\varepsilon_{t}^{\text {Key }}$ assume 1 , ou seja, em condições normais, $\gamma_{i, t}^{E x p}$ também será igual à unidade e as projeções permanecem conforme a lógica mostrada nas seções respectivas. Se o indicador aumenta, passa-se a acreditar que apenas parte do passado se reproduzirá, atingindo um mínimo de $89 \%$ da projeção, quando o IRI ultrapassa o padrão de referência máximo, indicando alto risco de solvência. Em condições 'normais', o passado recente é completamente projetado para o futuro de acordo com o grau de confiança. Em condições de restrição externa os agentes mudam o padrão de formação de expectativas e já não projetam integralmente o passado recente (em nível ou em taxa) em suas previsões de produção e de demanda por investimento.

Indicadores de insolvência e de iliquidez

A partir destes resultados é possível calcular alguns indicadores relevantes para explicar o movimento de capitais e a reação dos agentes diante da piora de tais indicadores. O primeiro deles é o já comentado indicador de risco de insolvência, $I R I_{t}$, calculado pela razão entre o passivo externo líquido e as exportações totais anualizadas. Esse indicador, conforme discutido por Medeiros \& Serrano (2001) e por Prates (2002), é relevante porque mostra a capacidade que as exportações terão de cobrir o estoque de passivo externo que ultrapassa as reservas ${ }^{43}$. Outro importante indicador é o de risco de iliquidez, que é dado pela razão entre o passivo externo de curto prazo e as reservas.

\section{Resultados das simulações}

Esta seção visa apresentar os resultados das simulações sob as seguintes hipóteses: i) versão padrão com inexistência de crescimento; ii) crescimento gerado pela dinâmica interna, supondo a inexistência de reação dos agentes diante da piora dos indicadores de solvência externa; iii) crescimento gerado pela dinâmica interna, com reação dos agentes ante a piora dos indicadores externos; e vi) crescimento gerado pela dinâmica interna, com reação dos agentes e com melhora na

(43) Segundo Prates (2002), valores acima de 7 estão historicamente associados a crises de BP em países em desenvolvimento. 
competitividade externa dos setores, obtida por meio do investimento autônomo inovativo. Pretende-se avaliar a dinâmica que o PIB assumirá sob os diferentes cenários.

\subsection{Resultados das simulações em condições padrão (Versão M1): 'ausência' de crescimento}

As simulações das condições padrão foram produzidas considerando constantes: as encomendas efetivas iniciais defasadas, o que produzirá vendas previstas constantes; os valores defasados das rendas das quatro classes; a taxa de crescimento da renda externa; e os valores iniciais defasados da renda nacional. Os gastos do governo são determinados de acordo com a meta de superávit, que varia entre $0,05 \%$ e $4,5 \%$ do PIB; e pelo estabilizador automático da relação dívida pública/PIB, que assume um valor positivo. Tais condições iniciais garantem a estabilização do modelo, já que não produzem crescimento induzido pela demanda, mantêm a estabilidade da relação dívida pública/PIB (Figura 2) ${ }^{44}$. O modelo apresenta uma trajetória cíclica para as variáveis.

\section{Variáveis Macro: PIB, Consumo e Investimento}

Na condição padrão espera-se que o PIB flutue, mas que não tenha uma tendência de crescimento expressiva, já que os mecanismos de geração de crescimento $^{45}$ foram calibrados para que a tendência de crescimento fosse mais próxima possível de zero. As trajetórias do PIB, do investimento e do consumo agregados podem ser observadas na Figura 1.

Figura 1

PIB, Consumo e Investimento ${ }^{46}$ (Versão M1)

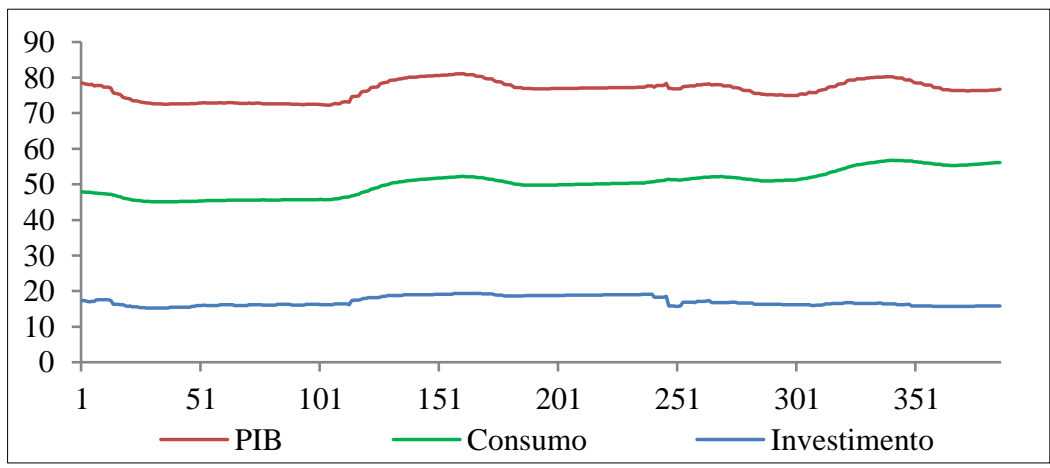

(44) Os resultados, por limitação de espaço, serão apresentados em nível agregado, exceto quando os benefícios de ilustração setorial forem indispensáveis.

(45) Os elementos de geração de tendência são: gastos privados autônomos e gastos públicos.

(46) Os períodos das simulações estão expostos no eixo horizontal e, exceto quando expresso em contrário, são períodos de produção. 
Nesta versão padrão, o consumo representa em média 65,5\% do PIB durante os períodos de simulação, e o investimento, 22,2\%. As taxas de crescimento anuais acumuladas, nominal e real, em todo o período são de respectivamente $0,002 \% \mathrm{e}$ $-0,13 \%$, e estão dentro do aceitável para a condição padrão.

\section{Variáveis do Setor Público}

Como já mencionado, no modelo padrão a meta de superávit poderá variar entre $0,05 \%$ e $4,5 \%$ do PIB e o estabilizador automático da relação dívida pública interna/PIB assume valor positivo. Isso permite que o crescimento não seja estimulado pelos gastos públicos, já que a estabilidade da dívida pública é uma das condições necessárias para produzir uma trajetória estável do PIB.

Figura 2

Variáveis do setor público (Versão M1)

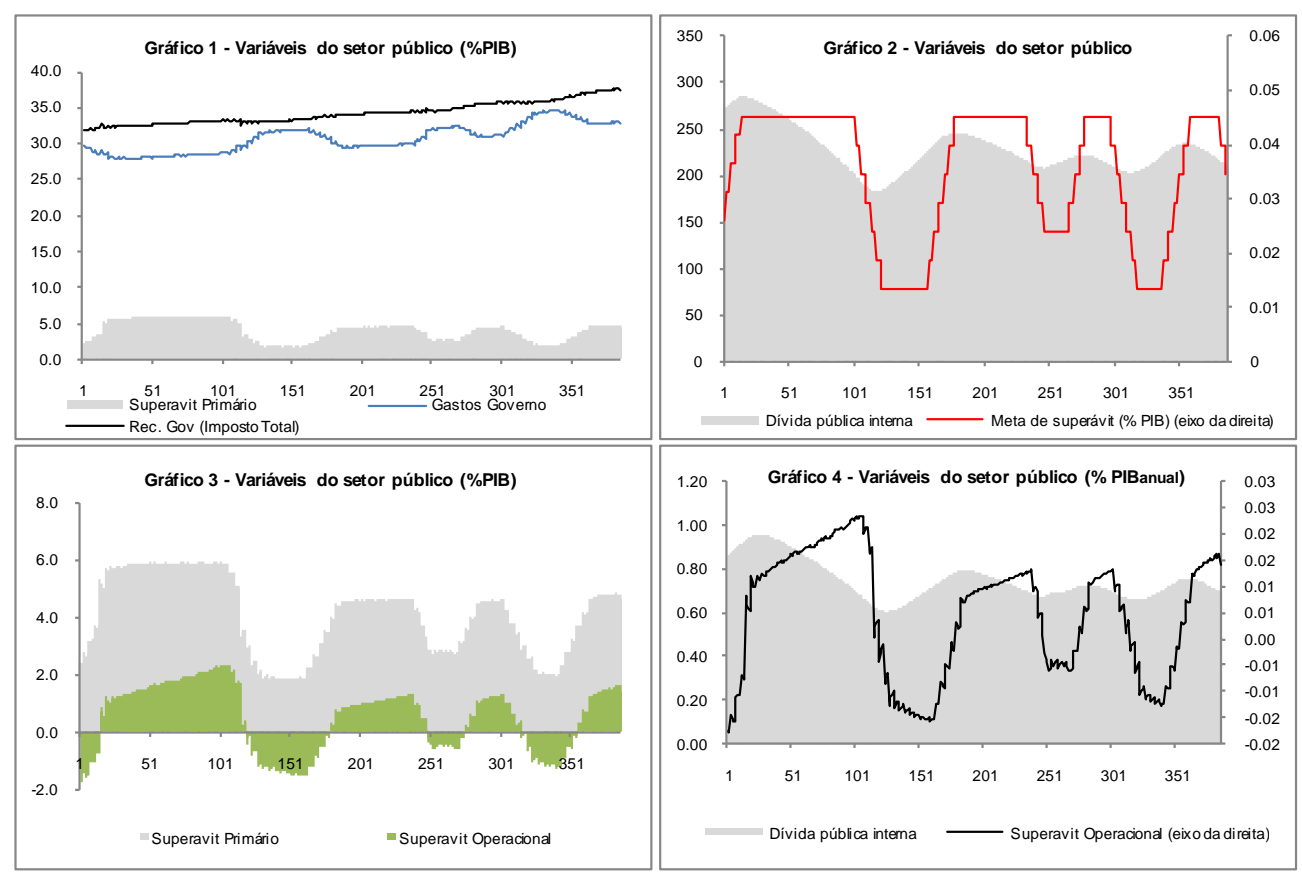

Conforme Figura 2 (gráficos 1 a 4), a meta de superávit efetiva variou de $1,3 \%$ a $4,5 \%$ do PIB. A dívida pública interna está estabilizada com uma leve tendência de queda e a relação dívida pública interna/PIB média no período foi de cerca de $67 \%$. Como esperado, o superávit operacional em proporção do PIB (Figura 2, gráfico 4) tem também um movimento cíclico que decorre de dois fatores: a flutuação da dívida pública interna gera pagamento de serviços - também cíclico sobre a dívida e o superávit primário também flutua como resultado do estabilizador automático da relação dívida/PIB. 


\section{Setor Externo}

Espera-se que as variáveis do setor externo reflitam as características de um país em desenvolvimento com algum grau de industrialização. Sob baixo ou nulo crescimento econômico, espera-se que os indicadores de solvência externa, o saldo em transações correntes (TC) e do BP não expressem risco iminente de vulnerabilidade externa.

Setor Externo - variáveis macroeconômicas e indicadores de insolvência

As exportações apresentam uma trajetória de pequeno crescimento, que decorre da taxa positiva de crescimento da renda mundial. As importações seguem a mesma trajetória do PIB. O saldo da balança comercial (BC) se mostra levemente positivo e crescente devido ao comportamento positivo observado nas exportações. Já o saldo das TC como proporção do PIB apresenta uma trajetória flutuante e se mostra, em média, levemente negativo (Figura 3, gráficos 1 e 2). Esse resultado coincide com o que se espera para países em desenvolvimento, que experimentam com frequência déficits em TC.

O saldo da conta de capital (Figura 3, gráfico 3) se mostra positivo, explicado pelo ingresso de IDE e pelo fluxo de capital financeiro, que se mostra estável, já que o diferencial de juros é constante e a taxa de câmbio nominal se valoriza até a metade dos períodos da simulação e se mantém na meta mínima após isso (Figura 4, gráfico 4).

Figura 3

Balanço de pagamentos, contas selecionadas (Versão M1)

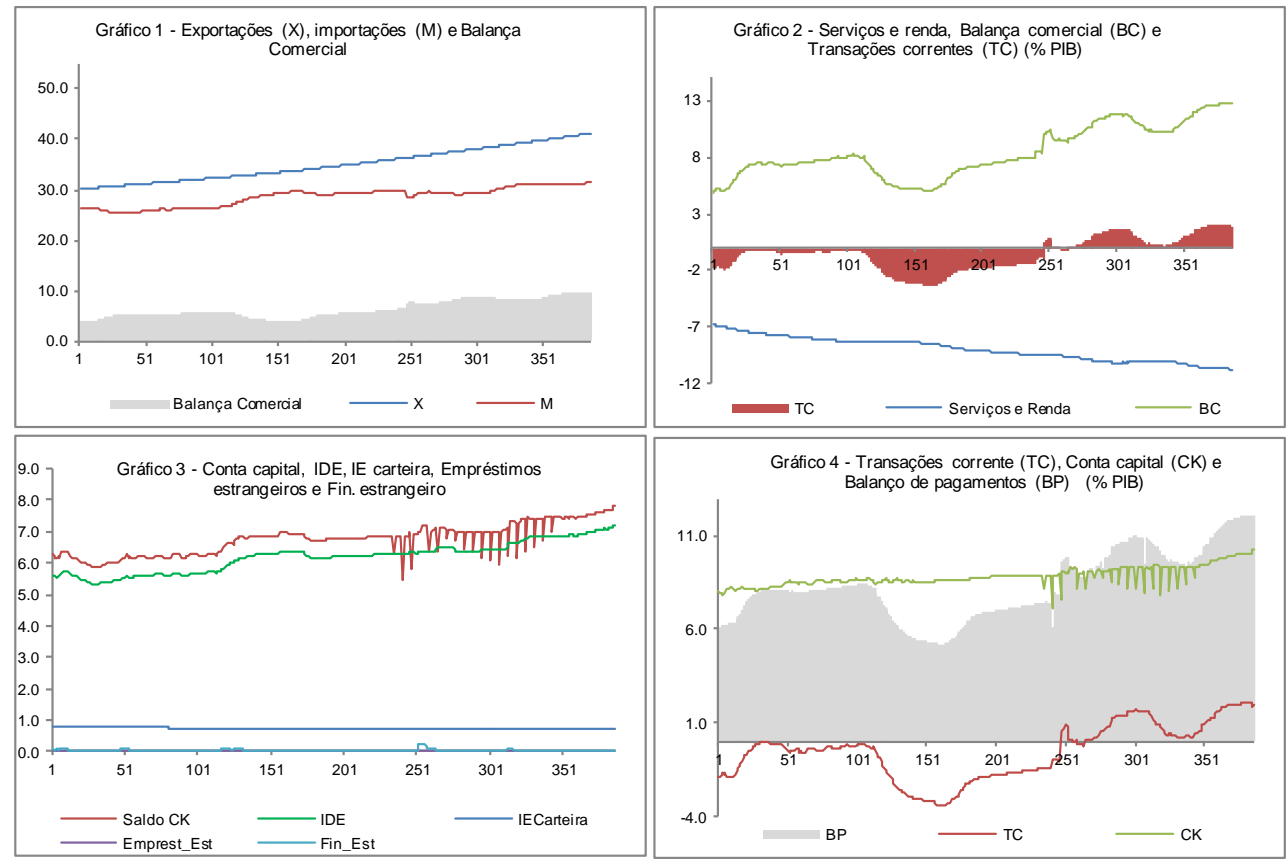


Os picos notados no saldo da conta de capital se referem ao fluxo de amortizações do estoque de dívida pagas pelo setor de serviços, já que seu endividamento atingiu o máximo desejado pelo setor e isso implica um sobreendividamento que deverá ser amortizado. Como parte dos empréstimos são contraídos no sistema financeiro internacional, há saída de capital referente ao pagamento de amortização pelo setor de serviços. O saldo do BP (Figura 4, gráfico 4) é o resultado de uma conta de capital positiva e de TC levemente positivas, o que gera um saldo positivo durante o período analisado, com tendência de crescimento.

Na Figura 4, o passivo externo (gráfico 1) é composto pelo estoque de IDE, de investimento em carteira e pelas dívidas pública e privada. A trajetória do passivo externo é explicada essencialmente pelo movimento de IDE, que é estável, mas que se acumula período a período, já que não há saída de IDE, exceto por remessa de lucros. Ao mesmo tempo em que cresce o passivo externo, crescem também as reservas (todos expressos em moeda nacional), de modo que o passivo externo líquido (passivo externo descontadas as reservas) permanece basicamente estável (gráfico 1). O indicador utilizado para guiar a reação dos agentes é o indicador de risco de insolvência (IRI).

Figura 4

Indicadores de Insolvência e Taxa de Câmbio (Versão M1)

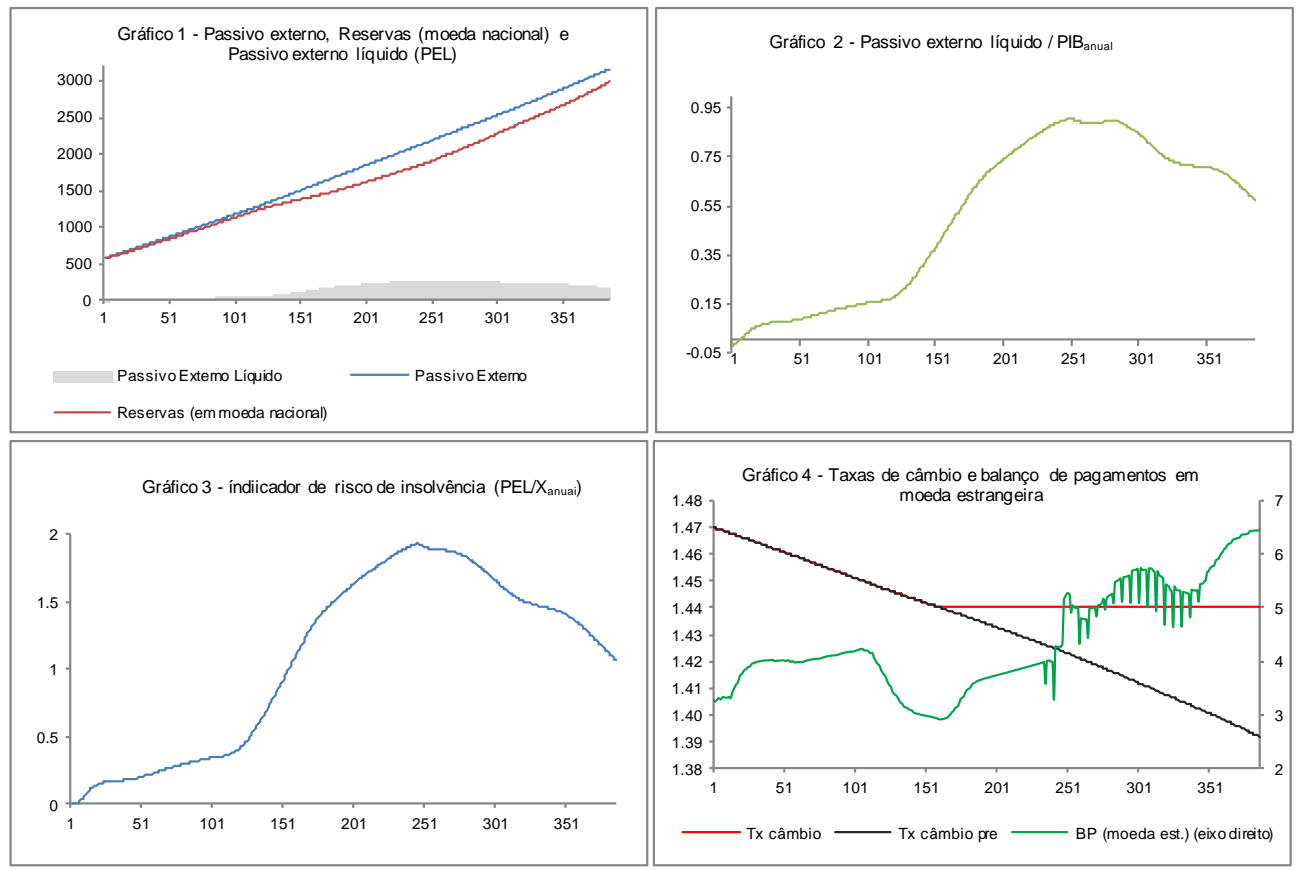

Como explicado na seção 2, valores superiores a 7 deste indicador estiveram relacionados a crises cambiais observadas em países em desenvolvimento. Nesta 
versão do modelo, o valor máximo para o IRI foi de 1,8 , indicando que o passivo externo líquido superou as exportações totais anuais em no máximo 80\% (gráfico 3) e que as condições de solvência se mantiveram favoráveis em um cenário de baixo crescimento. A taxa de câmbio nominal está sujeita a bandas cambiais impostas pelo governo e apresenta uma tendência de valorização devido aos sucessivos superávits no BP. A valorização é contida pela banda mínima e fica estabilizada neste valor (gráfico 4).

\subsection{Resultados das simulações com crescimento liderado pela dinâmica interna sem reação dos agentes às condições de solvência externa (Versão M2)}

O crescimento econômico estilizado nesta versão M2 foi gerado por dois fatores: (i) valores iniciais crescentes para as encomendas efetivas, influenciando as vendas previstas, a demanda por bens intermediários e por investimento; (ii) o valor da meta máxima de superávit do governo é inferior àquela do modelo padrão, permitindo que o governo gere menor superávit primário, de maneira que a relação dívida/PIB passa a ser crescente.

\section{Variáveis Macro: PIB e taxa de crescimento}

Na Figura 5 pode-se comparar as trajetórias do PIB entre o modelo padrão (M1) e a versão M2, com crescimento liderado pela dinâmica interna, quando os agentes não reagem à piora das condições externas.

Figura 5

PIB, Comparação Modelos M1 e M2

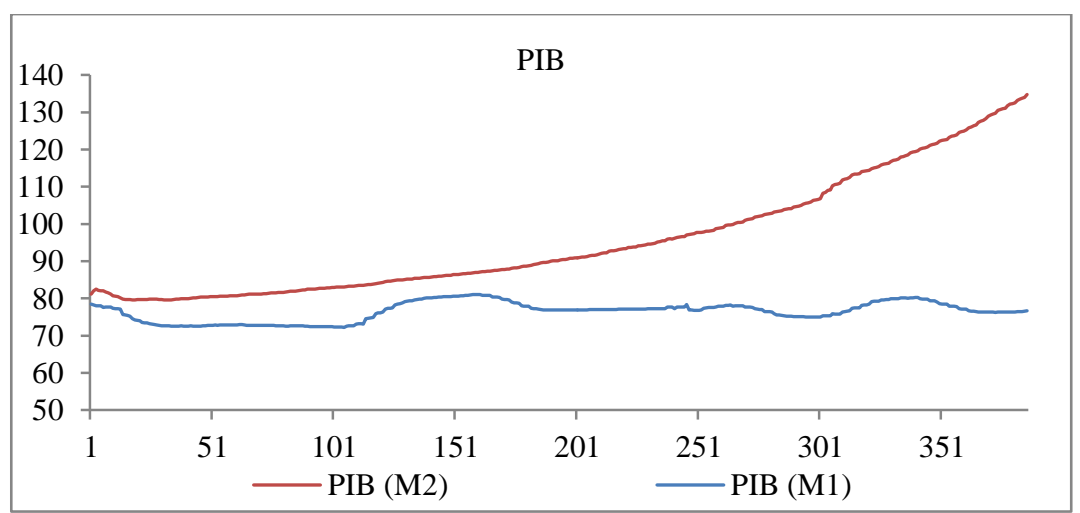

O PIB cresce de maneira mais expressiva, mostrada pela trajetória M2 acima. A taxa de crescimento anual nominal acumulada para todo o período passa de $0,002 \%$ no modelo padrão para uma taxa positiva de $53 \%$. Em termos reais, a taxa de crescimento acumulada foi respectivamente $-0,13 \%$ e $41 \%$ (M1 e M2). 


\section{Variáveis do setor público}

Na Figura 6 podem-se visualizar os dados do setor público. Um dos mecanismos utilizados para gerar crescimento foi permitir que o governo ampliasse seus gastos. A meta de superávit máxima foi fixada em $2 \%$ do PIB, quando no modelo padrão a meta poderia chegar a 4,5\%. O estabilizador automático da relação dívida/PIB faz a meta de superávit chegar rapidamente à máxima permitida, insuficiente para garantir a estabilidade da dívida, implicando um aumento da dívida pública em termos absolutos e relativos (gráficos 1 e 2).

Figura 6

Variáveis do setor público (Versão M2)

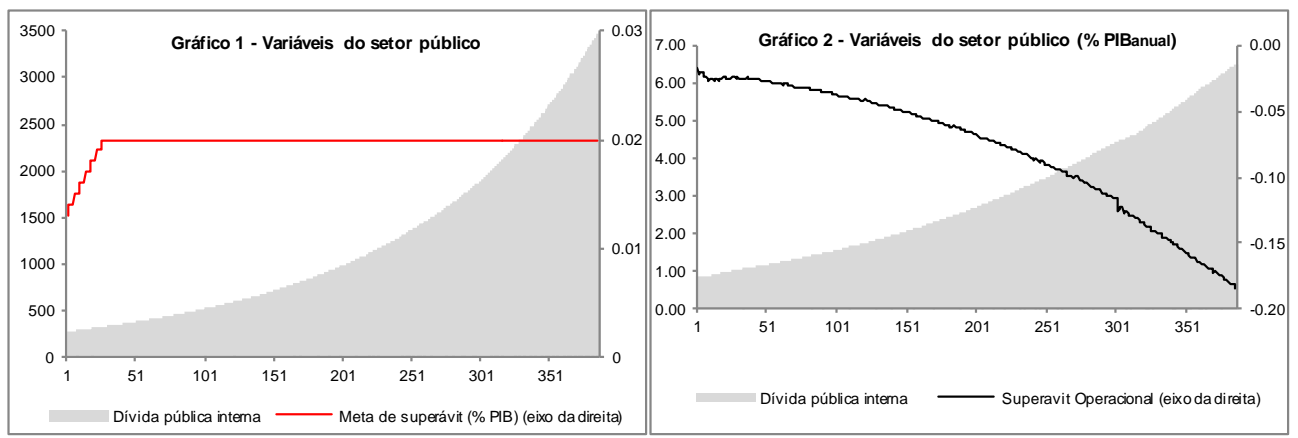

A meta de superávit não gera recursos suficientes para cobrir as despesas com pagamento de juros sobre a dívida pública, implicando um aumento do déficit operacional (gráfico 2) a uma taxa crescente.

\section{Setor externo}

O foco central novamente recai sobre o setor externo. Pretende-se observar o resultado sobre as contas externas do crescimento econômico liderado exclusivamente pela dinâmica interna, mantida a taxa de crescimento da economia mundial igual à da versão M1.

\section{Setor externo - variáveis macroeconômicas e indicadores de insolvência}

O crescimento do PIB é acompanhado pelo crescimento das importações agregadas de bens de consumo, de insumos e de bens de capital. As exportações respondem fortemente à taxa de crescimento mundial, como na versão M1. Com o tempo, as importações ultrapassam as exportações em valores absolutos e a economia começa a incorrer em déficit comercial (Figura 7, gráfico 1). Tal resultado piora o saldo em TC, ampliando o déficit em proporção do PIB (gráfico 2) acarretando um menor ingresso de divisas para fazer frente à saída de capitais. A conta de capital continua com saldo positivo, resultado da manutenção da entrada de 
investimento em carteira e do fluxo de investimento direto estrangeiro, que se mantém positivo e crescente. No entanto, a entrada de capital não é suficiente para cobrir o déficit de TC. Como resultado, o BP começa a ficar negativo a partir de certo ponto (próximo ao período 250) e atinge -6\% do PIB (gráfico 4).

Figura 7

Balanço de Pagamentos, contas selecionadas (Versão M2)

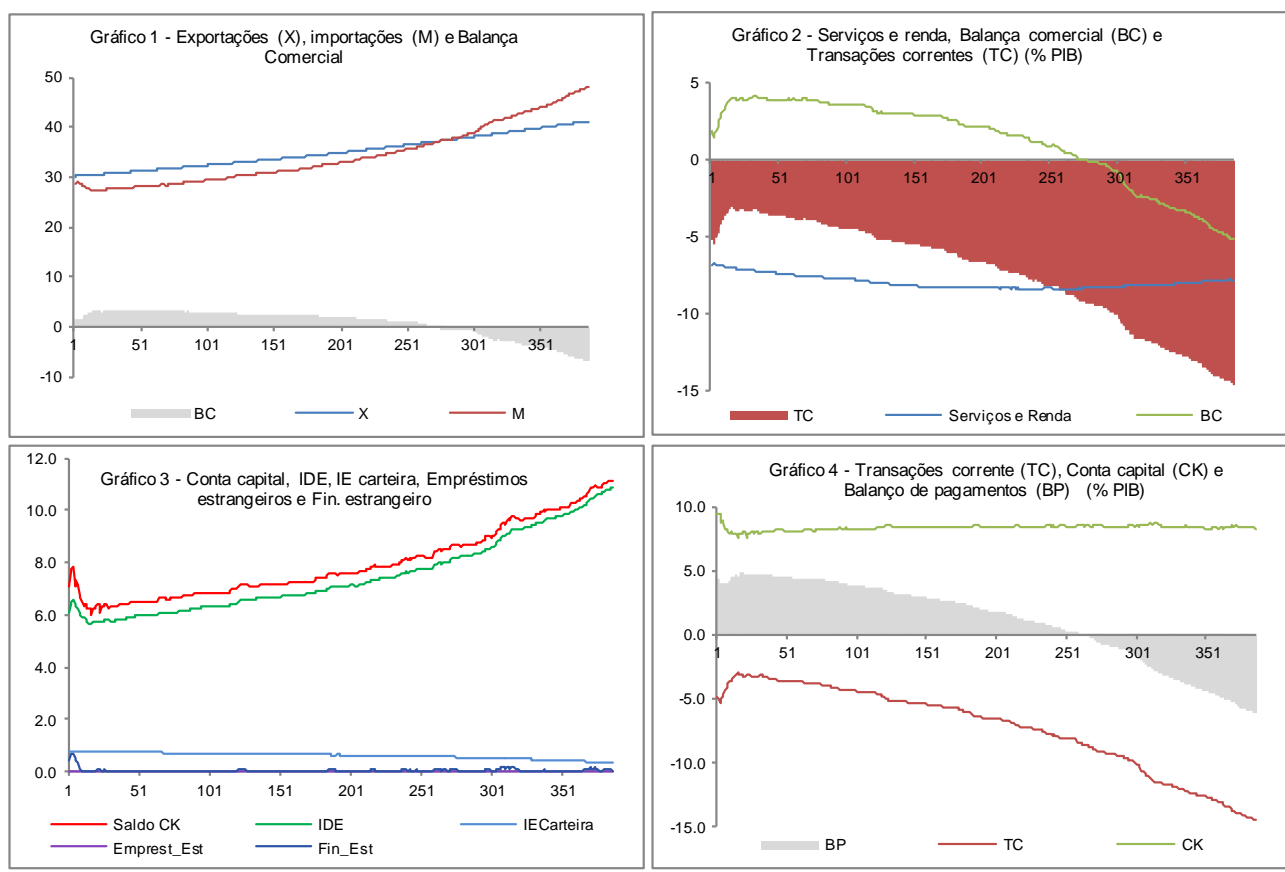

Na Figura 7 veem-se os resultados da deterioração dos saldos do BP sobre o passivo externo. Em uma economia com as características da brasileira, com crescimento intensivo em importação, a indução do crescimento pela dinâmica interna leva a déficits no BP e provoca aumento do passivo externo e do passivo externo líquido, provocando deterioração das reservas, que entram em uma trajetória de queda (gráfico 1 e 2).

Os indicadores de solvência externa na Figura 8 mostram que o IRI ultrapassa o valor de referência considerado seguro (gráfico 1). Nesta simulação um contexto em que os agentes não reagem à piora dos indicadores externos - foi possível observar crescimento econômico com contínua deterioração das contas externas, um resultado à la Thirlwall \& Hussain. A literatura teórica e empírica enfatiza, porém, que diante da piora de um ou mais indicadores os agentes tendem a se inquietar. A reação dos agentes ante a piora dos indicadores de solvência externa tende a restringir o crescimento e será tema da próxima subseção. 
Figura 8

Indicadores de Solvência (Versão M2)

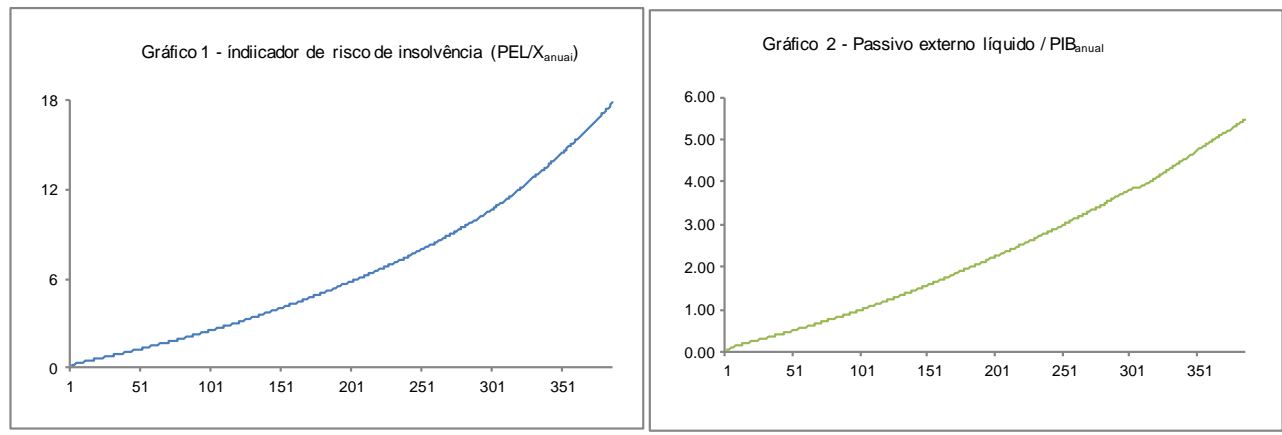

\subsection{Resultados das simulações com crescimento liderado pela dinâmica interna com reação dos agentes às condições externas (Versão M3)}

Neste item é feita a mesma simulação da subseção anterior, no entanto, incluiu-se a reação dos agentes diante da piora dos indicadores de vulnerabilidade externa ${ }^{47}$. A exposição está centrada na trajetória do PIB, em sua taxa de crescimento e nas variáveis relativas ao setor externo.

Se o IRI ultrapassa 8 (por hipótese, valor mínimo a partir do qual os agentes reagem), as expectativas são revisadas para baixo e o grau de confiança nas mesmas também diminui, afetando as projeções sobre vendas esperadas e o investimento desejado; a remessa de lucros sobe e sua contrapartida, o reinvestimento de capital estrangeiro, cai. Há afluxo de investimento em carteira e o fluxo de IDE cairá, reduzindo a participação estrangeira nos setores. Esses movimentos em conjunto levam à redução das vendas previstas pelos setores, impactando negativamente suas decisões de produzir e de investir.

\section{Variáveis Macro: PIB e taxa de crescimento}

Os resultados comparativos em termos de PIB dos dois modelos estão expressos na Figura 9. Estes mostram que numa economia estilizada com crescimento liderado pela dinâmica interna, gerando aprofundamento do déficit em transações correntes e no BP e piora dos indicadores externos, a trajetória de crescimento em algum momento será interrompida pela reação dos agentes diante de sua percepção de risco.

(47) Conforme descrito na segunda seção, o IRI é o indicador utilizado para modelar a reação dos agentes diante da piora das condições externas. 
Figura 9

PIB, Comparação Versões M2 e M3

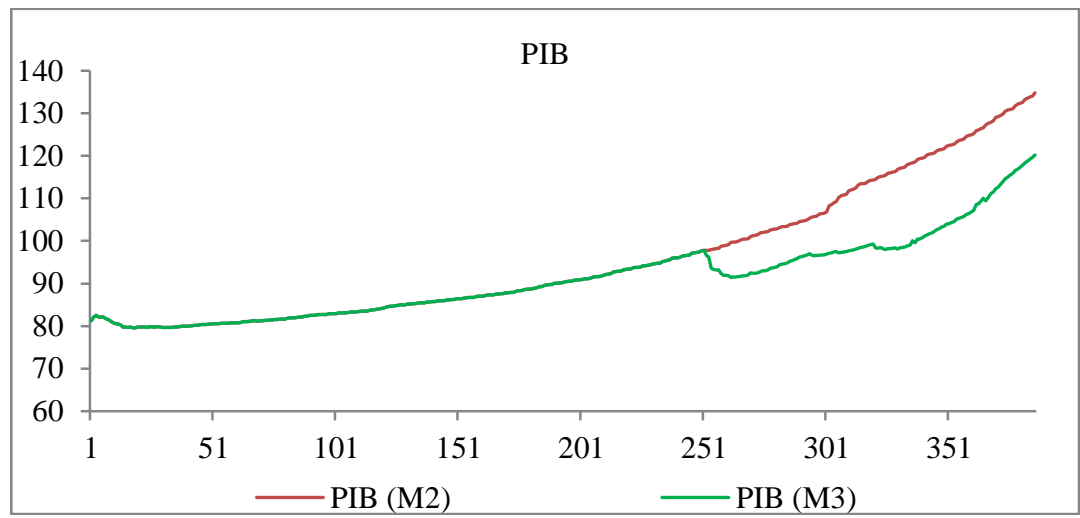

O reflexo da reação dos agentes, que será apresentada a seguir, pode ser expresso em termos de redução da taxa de crescimento do PIB acumulado em termos nominais (de 53\% no M2 para 42\% no M3) e em termos reais (de $42 \%$ no M2 para $31 \%$ no M3). O PIB apresenta taxas oscilantes a partir aproximadamente da rodada 250, quando o IRI ultrapassa o limite máximo considerado aceitável pelos agentes. Aqui apresentaremos as variáveis setoriais relativas ao setor externo, consideradas fundamentais para ilustrar as reações:

\section{Setor externo - variáveis setoriais}

A reação dos agentes diante da fragilização externa está expressa na Figura 10. A disponibilidade de recursos de IDE (gráfico 3) já não mais equivale à proporção da participação estrangeira setorial no investimento desejado. Os recursos disponíveis de IDE caem para $40 \%$ da participação estrangeira enquanto o IRI estiver na primeira faixa de reação (entre 8 e 10,5), e para 20\% da participação estrangeira quando o indicador ultrapassa 10,5 (ver indicador de insolvência na Figura 12). Além disso, a remessa de lucro para o exterior aumenta e o reinvestimento relativo à participação estrangeira cai. Desse conjunto de movimentos decorre a queda observada (gráfico 2) na participação estrangeira setorial. A lógica de reação das variáveis setoriais é aquela apresentada no capítulo 2 .

Os coeficientes de exportação sofrem ligeiro aumento (gráfico 1): as exportações setoriais aumentam, já que o crescimento mundial não mudou, enquanto as vendas internas de cada setor caem. 
Figura 10

Variáveis setoriais externas e mudança nas expectativas (Versão M3)

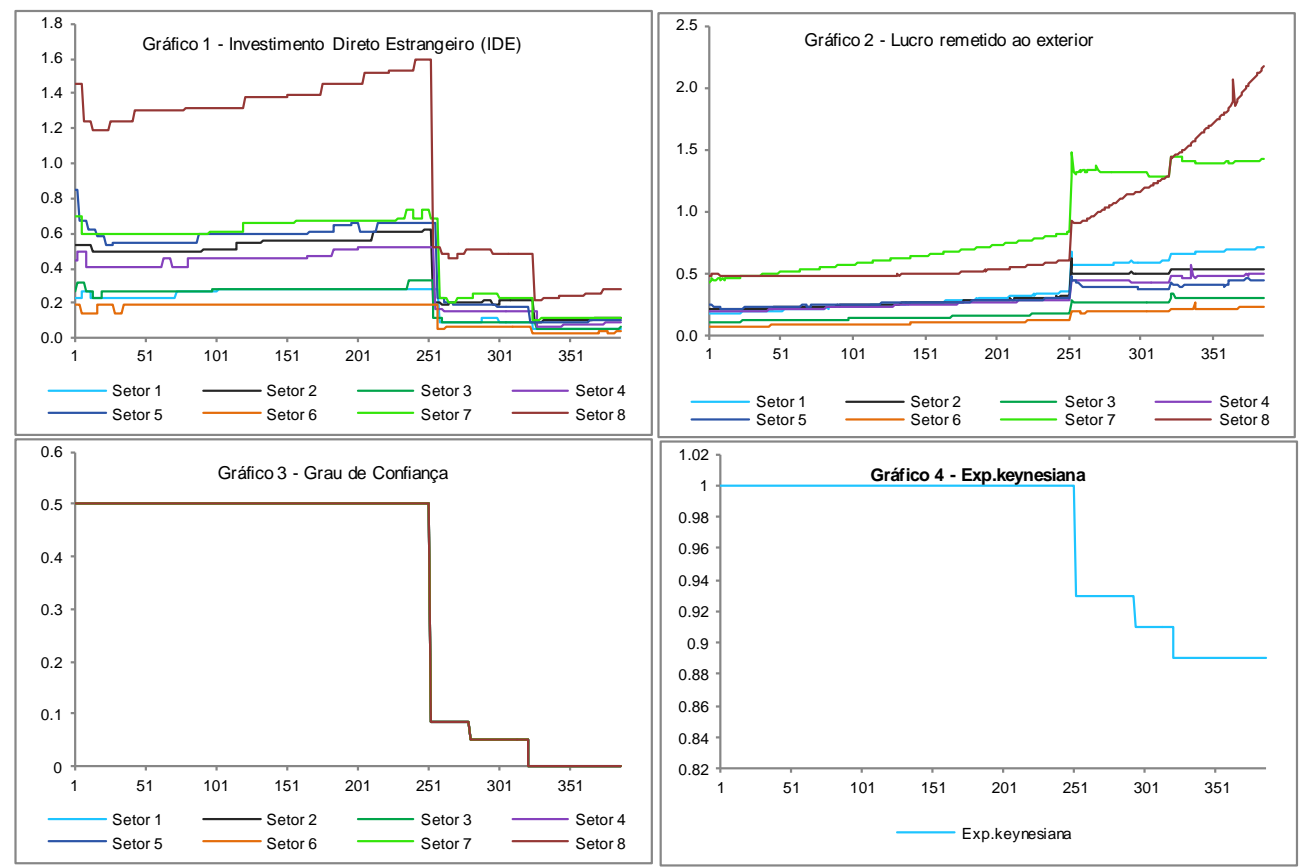

O grau de confiança dos agentes em suas expectativas cai e o padrão de formação de expectativas muda. O grau de confiança nas expectativas (gráfico 3), projetadas a partir das encomendas efetivas passadas para definir a produção e a demanda por insumos e por investimento dos setores, cai a zero quando o IRI ultrapassa o valor de referência máximo. Quanto isso acontece, projeta-se para o futuro apenas a média das encomendas efetivas ocorridas no último período de referência ${ }^{48}$, ou seja, não se repete a taxa observada de crescimento, mas a média do nível das encomendas efetivas defasadas. Além disso, o próprio padrão de formação das expectativas muda, sendo revisadas de forma a não mais projetar integralmente o passado recente para o futuro próximo. O novo padrão de formação das expectativas consiste em projetar apenas parcialmente a média das encomendas efetivas passadas para definir as decisões de produzir e de investir.

\section{Setor externo - variáveis macroeconômicas e indicadores de insolvência}

O aumento da exposição ao risco leva a saídas de capital de curto prazo (investimento em carteira) que podem ser vistas no gráfico 3 da Figura 11. Esse movimento, em conjunto com a redução na entrada de IDE, faz o saldo da conta de

(48) Para a produção programada e a demanda por insumos se utilizou a média dos dois últimos períodos e para a decisão de investimento a média dos seis últimos. 
capital cair a zero, com uma ligeira recuperação, já que o diferencial de juros se mantém e os fluxos de investimento em carteira têm uma ligeira recuperação.

O saldo em transações correntes como proporção do PIB segue uma trajetória de deterioração, tornando-se menos negativo após a reação dos agentes (rodada 250), resultado conjunto da redução das importações devido à queda do PIB e da manutenção das exportações (gráfico 1 e 2). A conta de serviços e renda (soma do lucro reinvestido, lucro remetido e juros remetidos) também apresenta uma piora devido ao aumento do lucro remetido (gráfico 2). O saldo do BP como proporção do PIB é bastante instável após a reação dos agentes, mas, conforme esperado, se torna muito mais negativo, levando ao rápido consumo das reservas (Figura 11, gráfico 4).

Figura 11

Balanço de Pagamentos, contas selecionadas (Versão M3)
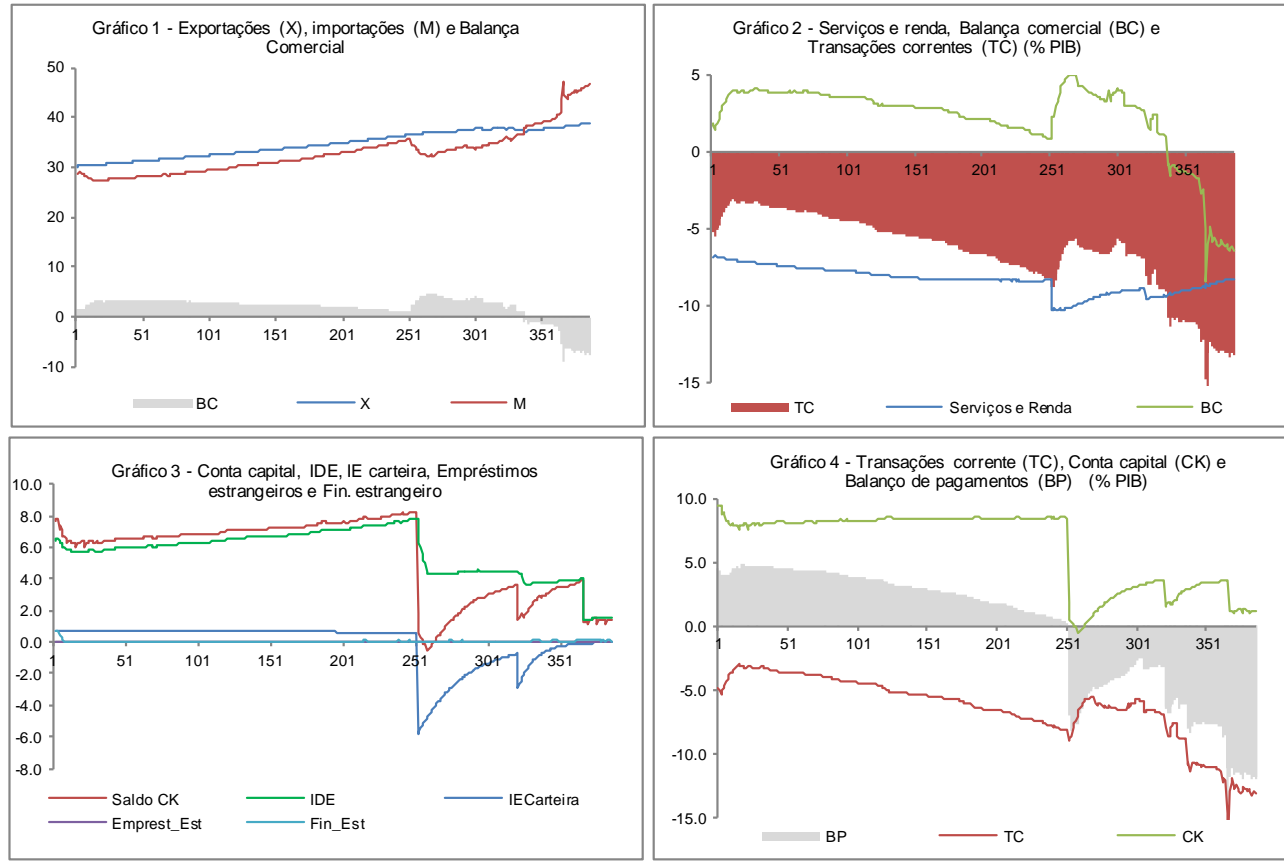

Os dados relativos ao passivo externo estão expressos na Figura 12. O passivo externo sofre uma inflexão em sua trajetória devido à saída de investimentos em carteira, à maior remessa de lucros e à redução da entrada de IDE. Tal dinâmica dos fluxos de capitais acelera a deterioração das reservas. Assim, tanto a trajetória do passivo externo como a das reservas sofrem inflexão, disso resultando que o IRI permanece elevado (gráficos 1 a 4). 
Figura 12

Indicador de Insolvência e Taxa de Câmbio (Versão M3)

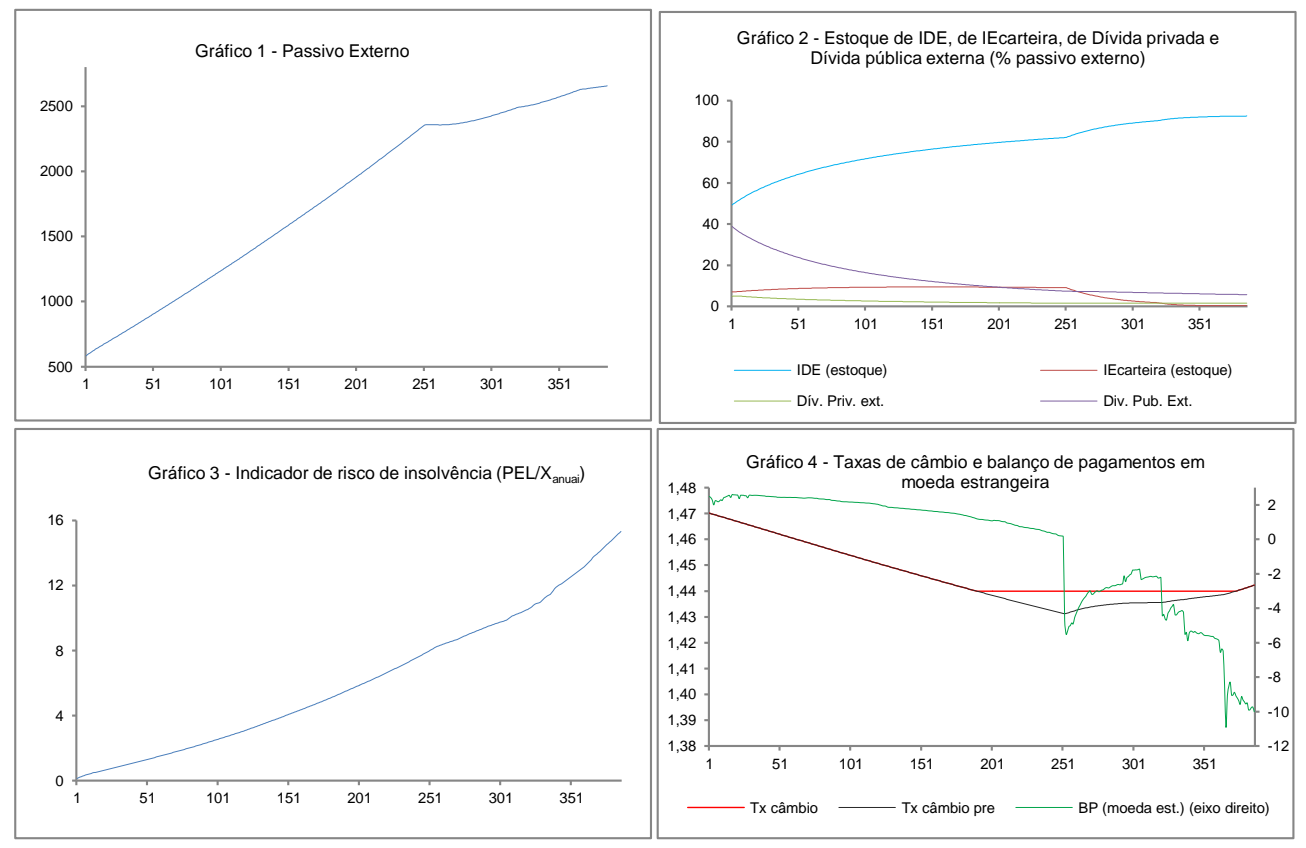

As reservas caem mais rapidamente que no modelo sem reação dos agentes, e tanto o passivo externo em proporção do PIB como o indicador de insolvência crescem menos que no modelo sem reação, mas continuam elevados mesmo após a reação dos agentes. Isso decorre essencialmente do fato de que a política econômica não mudou e o governo deu continuidade à sua política de déficits operacionais e de manutenção de um superávit máximo de $2 \%$. A flexibilização dessa política, em que o governo também passe a reagir aos indicadores de insolvência externa, não será simulada nesta versão.

\subsection{Crescimento liderado pela dinâmica interna com reação dos agentes, introduzindo maior competitividade relacionada ao investimento autônomo (Versão M4)}

A análise do crescimento econômico e de suas possibilidades em uma economia em desenvolvimento não pode prescindir, em uma perspectiva estruturalista, da consideração da estrutura produtiva e da inserção externa da economia. Nesta versão, faremos uma alteração estilizada em relação à versão anterior (M3). As variações do investimento autônomo, como descrito na seção 2, são uma proxy para as variações da competitividade média dos setores e afetam o coeficiente de exportação dos mesmos. Assim, o parâmetro de modernização produtiva setorial será incrementado, aumentando proporcionalmente mais nos 
setores produtores de insumos e de bens de capital, tornando-os mais competitivos internacionalmente.

Como resultado, o PIB apresenta uma trajetória em nível mais elevado e a restrição externa é afastada para o final do período de análise. A Figura 13 a seguir mostra o resultado do PIB comparado dos dois modelos. Na versão M3 a restrição comprime o PIB aproximadamente no passo 251 , enquanto na versão M4, como resultado da melhora dos coeficientes de exportação, a restrição somente se impõe 100 passos depois, para um nível do PIB muito superior.

Figura 13

PIB, Comparação Versões M3 e M4

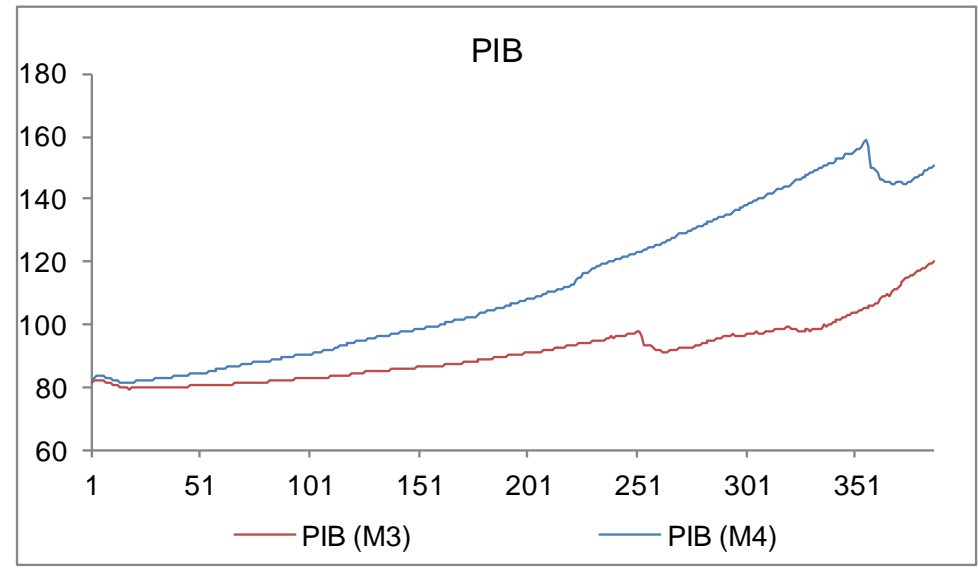

A trajetória do PIB se mostra mais consistente e as taxas de crescimento mais expressivas, alcançando $64 \%$ de crescimento anual nominal acumulado e $46 \% \mathrm{em}$ termos reais, contra $42 \%$ e $31 \%$ respectivamente na versão M3.

A Figura 14 mostra os dados relativos ao setor externo em nível mais agregado. No gráfico 1 pode-se notar que a trajetória das exportações é muito mais favorável em comparação às versões de crescimento anteriores. $\mathrm{O}$ impulso dado ao PIB pelo crescimento das exportações é acompanhado por importações crescentes, que não ultrapassam as exportações. $\mathrm{O}$ saldo da $\mathrm{BC}$ é positivo durante todo o período. O saldo em TC é negativo, mas como proporção do PIB atinge patamares inferiores aos das versões com crescimento, já que a restrição externa foi "empurrada" para a frente. O saldo do BP somente fica negativo aproximadamente no período 351, imediatamente após o IRI atingir níveis acima do padrão aceitável (Figura 15). Neste momento há reversão da entrada de IE em carteira, e o IDE também cai abruptamente, tornando o saldo do BP negativo. Há uma substancial melhora no saldo de transações correntes, uma vez que a mudança nas expectativas 
e atitudes dos agentes levou à queda do PIB e, por conseguinte, das importações, mantidas as exportações (gráfico 1 e 2).

\section{Figura 14}

Balanço de Pagamentos, contas selecionadas (Versão M4)
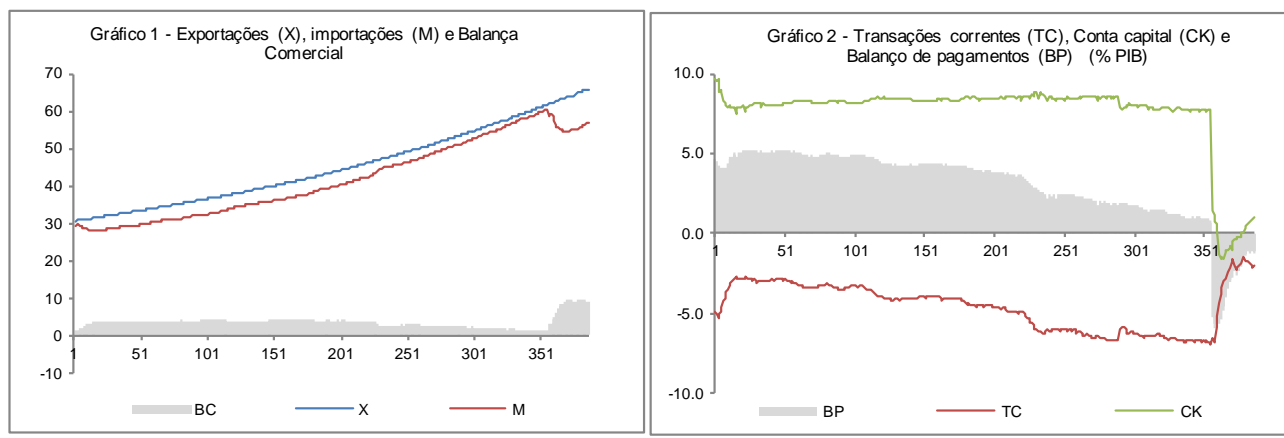

O IRI fica abaixo do padrão limite a partir do qual os agentes reagem até a rodada 351, ou seja, se o investimento autônomo é mais inovativo e induz ao aumento das exportações, haverá melhora nas condições externas de modo que a restrição externa demorará mais tempo para restringir o crescimento da demanda e do PIB.

Figura 15

Indicadores de Insolvência (M4)
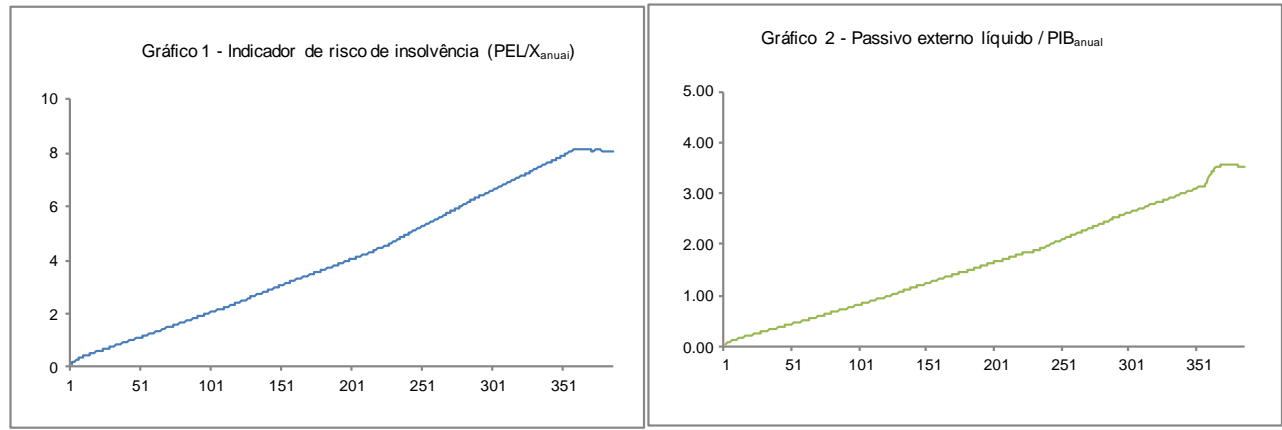

\section{Conclusões}

Utilizando instrumental de simulação, o artigo buscou mostrar que, em uma economia em desenvolvimento estilizada, a adoção de certos padrões de crescimento poderá ter alcance limitado, uma vez que a restrição externa em algum momento se impõe e acaba limitando o crescimento da demanda e do produto. Além disso, mostrou-se que, em um modelo com padrão de crescimento liderado exclusivamente 
pela dinâmica interna, com crescimento intensivo em importações - o que é característico de países em desenvolvimento - para dados padrões de crescimento mundial e de exportações -, acaba gerando saldos comerciais negativos que podem ser financiados por divisas ou via acúmulo de passivo externo. No entanto, quando os agentes reagem ao acúmulo de passivo externo, a restrição externa é efetiva e limita o crescimento, mostrando que não é possível crescer indefinidamente com crescentes déficits no balanço de pagamentos.

Em seguida mostramos que a restrição externa e, portanto, a trajetória do PIB, podem ser positivamente flexibilizados caso as decisões de investimento autônomo setorial sejam capazes de contribuir para a transformação da estrutura produtiva, afetando positivamente a competitividade externa e o coeficiente de exportação. Ou seja, ao se inserir no modelo uma hipótese de que os gastos em investimento afetam mais significativamente a competitividade dos setores, os resultados das simulações mostraram que esta melhora competitiva empurrou a restrição externa para períodos mais distantes e produziu efeitos positivos no PIB, sinalizando uma saída de política para que países como o Brasil enfrentem de forma estrutural a questão da restrição externa.

Pode-se concluir que há um limite além do qual as políticas exclusivamente internas de estímulo à demanda não conseguem alçar a economia a taxas mais expressivas de crescimento, exceto se tais políticas forem combinadas com melhora nas condições externas ${ }^{49}$ ou se forem capazes - direta ou indiretamente - de alterar a estrutura produtiva na direção de maior competitividade, flexibilizando a restrição externa. Desse modo, pode-se concluir que o caminho sustentável para o crescimento, do ponto de vista da restrição externa, seria a reconfiguração da pauta de exportações, melhorando o padrão de especialização e reduzindo a dependência da dinâmica externa. Embora isso não requeira que essa economia se torne um grande exportador de algum tipo específico de produto, evidencia a necessidade de se consolidar um setor produtor de bens de capital, reduzindo a elasticidade-renda da importação deste tipo de bem, de forma a aliviar a pressão sobre as importações quando a economia e o investimento crescem.

Os resultados obtidos ratificam as contribuições heterodoxas sobre o tema ao mostrarem que é possível dar início a uma trajetória de crescimento impulsionada pelo consumo autônomo, pelo investimento autônomo ou por gastos públicos; o aumento da demanda, entretanto, provocará aumento das importações e, se as exportações não acompanharem o crescimento da taxa que remunera o passivo externo, em algum momento a demanda deverá ser contida, restringindo o crescimento, que esbarrou no teto da restrição externa.

(49) Resultados não apresentados nesta versão. 


\section{Referências bibliográficas}

BARBOSA-FILHO, N. H. International liquidity and growth in Brazil. Center for Economic Policy Analysis, New School University, 2001. (Working Paper).

BARBOSA-FILHO, N. H. The balance-of-payments constraint: from balanced trade to sustainable debt. Banca Nazionale Del Lavoro Quarterly Review, n. 219, p. 381-399, 2002.

BUSATO, M. I. Crescimento econômico e restrição externa: um modelo de simulação. Rio de Janeiro: Beco do Azougue, 2012.

BIELSCHOWSKY, R. Cinqüenta anos de pensamento na Cepal: uma resenha. Rio de Janeiro: Record, 2000. v. 1.

FERRARI, M. A. R.; FREITAS, F. N. P.; BARBOSA-FILHO, N. B. O papel da taxa de câmbio real nos modelos de restrição externa: uma proposta de releitura com elasticidades endógenas. In: ENCONTRO DA ASSOCIAÇÃO KEYNESIANA BRASILEIRA, ago. 2010. 29p.

GALA, P. Política cambial e macroeconomia do desenvolvimento. 134f. Tese (Doutorado)-Fundação Getúlio Vargas, São Paulo, 2006.

HARROD, R. An essay in dynamic theory. The Economic Journal, v. 49, n. 193, p. 14-33, Mar. 1939.

KAMINSKY, G.; LISONDO, S.; REINHART, C. Leanding indicators of currency crises. IMF Staff Papers, v. 45, n. 1, Mar. 1998.

KALECKI, M. [1954]. Teoria da dinâmica econômica. São Paulo: Editora Abril, 1983.

KALECKI, M. [1968]. Tendência e ciclo econômico. In: MIGLIOLI, J. (Org.). Crescimento e ciclo das economias capitalistas. São Paulo: Hucitec, 1987.

KEYNES, J. M. [1936]. A teoria geral do emprego, do juro e da moeda. Tradução de Mário R. da Cruz; Revisão técnica de Cláudio R. Contador. São Paulo: Atlas, 1982. 328p.

KEYNES, J. M. [1937]. A teoria geral do emprego. In: SZMRECSANYI, T. John Maynard Keynes: economia. São Paulo: Ática, 1984. p.167-179.

McCOMBIE, J.; THIRLWALL, A. Economic growth and the balance-of-payments constraint. St. Martin's Press, 1994. 601p.

MEDEIROS, C.; SERRANO, F. Inserção externa, exportações e crescimento no Brasil. In: FIORI. J.; MEDEIROS, C. (Org.). Polarização mundial e crescimento. Petrópolis: Vozes, 2001. 
MORENO-BRID, J. C. On capital flows and the balance-of-payments constrained growth model. Journal of Post Keynesian Economics, v. 21, n. 2, p. 283-298, 199899.

POSSAS, M. L. A dinâmica da economia capitalista: uma abordagem teórica. São Paulo: Editora Brasiliense, 1987.

POSSAS, M. L. Demanda efetiva, investimento e dinâmica: a atualidade de Kalecki para a teoria macroeconômica. In: POMERANZ, L. et. al. (Org.) Dinâmica econômica do capitalismo contemporâneo. São Paulo: Edusp, 2001

POSSAS, M. L. Um modelo dinâmico multissetorial. Pesquisa e Planejamento Econômico, v. 14, n. 2, ago, 1984.

POSSAS, M. L.; DWECK Esther; VISCONTI Ana Cristina Reif. Um modelo macrodinâmico multissetorial. Rio de Janeiro: IE-UFRJ, 2004. (Textos para Discussão, 003).

PRATES, D. Crises financeiras dos países "emergentes": uma interpretação heterodoxa. 203f. Tese (Doutorado)- IE-Unicamp, Campinas, 2002.

PREBISCH, R. Problemas teóricos e práticos do crescimento econômico. In: BIELSCHOWSKY, R. Cinqüenta anos de pensamento na Cepal. Rio de Janeiro: Record, 2000. v. 1.

REIF, A. C. Restrição do balanço de pagamentos ao crescimento: um modelo multissetorial aberto. 226f. Tese (Doutorado)-IE-UFRJ, Rio de Janeiro, 2006.

THIRLWALL, A. P. A natureza do crescimento econômico: um referencial alternativo para compreender o desempenho das nações. Brasília: Ipea, 2005. 112p.

THIRLWALL, A. P. The balance of payments constraint as an explanation of international growth rate differences. Banca Naz. Del Lavoro Quarterly Review, v. 128, p. $45-53,1979$.

THIRLWALL, A. P.; HUSSAIN, N. The balance of payments constraint, capital flows and growth rate differences between developing countries. Oxford Economic Papers, v. 34, n. 3, p. 498-510, Nov. 1982. 